\title{
The Relationship Between Social Skills and Problem Behaviors in Adolescent Males with Autism Spectrum Disorders
}

\author{
Amanda Armstrong Randall \\ West Virginia University, ararmstrong@mix.wvu.edu
}

Follow this and additional works at: https://researchrepository.wvu.edu/etd

Part of the Applied Behavior Analysis Commons, Disability Studies Commons, and the Special

Education and Teaching Commons

\section{Recommended Citation}

Randall, Amanda Armstrong, "The Relationship Between Social Skills and Problem Behaviors in Adolescent Males with Autism Spectrum Disorders" (2019). Graduate Theses, Dissertations, and Problem Reports. 4055.

https://researchrepository.wvu.edu/etd/4055

This Dissertation is protected by copyright and/or related rights. It has been brought to you by the The Research Repository @ WVU with permission from the rights-holder(s). You are free to use this Dissertation in any way that is permitted by the copyright and related rights legislation that applies to your use. For other uses you must obtain permission from the rights-holder(s) directly, unless additional rights are indicated by a Creative Commons license in the record and/ or on the work itself. This Dissertation has been accepted for inclusion in WVU Graduate Theses, Dissertations, and Problem Reports collection by an authorized administrator of The Research Repository @ WVU.

For more information, please contact researchrepository@mail.wvu.edu. 
The Relationship Between Social Skills and Problem Behaviors in Adolescent Males with Autism Spectrum Disorders

\author{
Amanda Armstrong Randall \\ Dissertation submitted \\ to the College of Education and Human Services \\ at West Virginia University \\ in partial fulfillment of the requirements for the degree of \\ Doctor of Education \\ Reagan Curtis, Ph.D., Chair \\ Kristin Moilanen, Ph.D. \\ Abhik Roy, Ph.D. \\ Trevor Stokes, Ph.D. \\ Department of Learning Sciences and Human Development
}

\title{
Morgantown, West Virginia
}

2019

Keywords: Autism, Adolescents, Social Skills, Social Skills Training, Problem Behavior Copyright 2019 Amanda Armstrong Randall 


\begin{abstract}
The Relationship Between Social Skills and Problem Behaviors in Adolescent Males with Autism Spectrum Disorders

\section{Amanda Armstrong Randall}

Adolescent males with autism spectrum disorder commonly display an increased prevalence of problem behaviors and persistent deficits in social skills when compared to their typically developing peers. The present study deployed a single subject, multiple-baseline design to investigate the use of the social skills training program Super Skills: A Social Skills Group Program for Children with Asperger Syndrome, High-Functioning Autism and Related Challenges to promote enhanced social skills and minimize problem behaviors. Two groups of adolescent males with autism $(N=6)$ participated in weekly social skills training groups also containing typically developing peers $(N=3)$ once a week over an eight-week period. Results from this investigation indicated that social skills training was effective at increasing student fundamental social skills and social initiation skills. Teachers also reported improved relationships amongst the students with autism. Findings did not support a consistent decrease in problem behaviors for all individuals with autism.
\end{abstract}

Keywords: Autism, Adolescents, Social Skills, Social Skills Training, Problem Behaviors 


\section{Table of Contents}

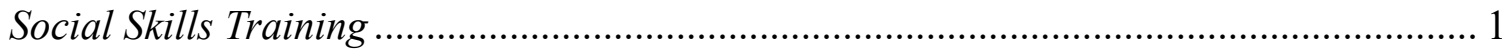

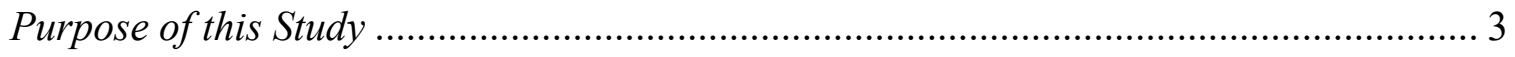

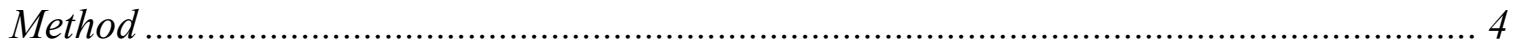

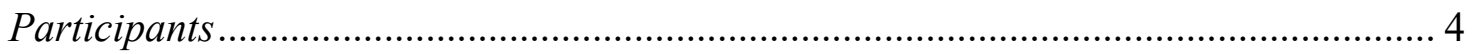

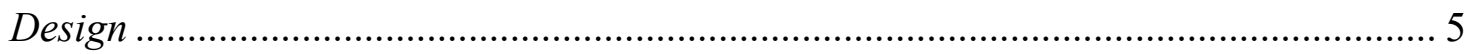

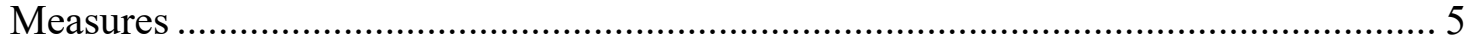

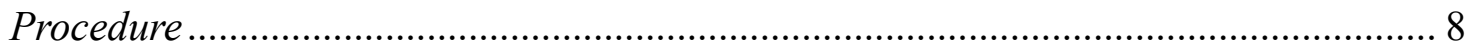

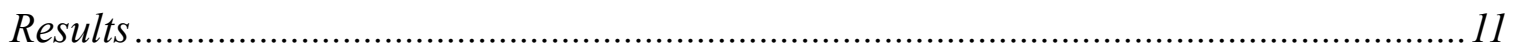

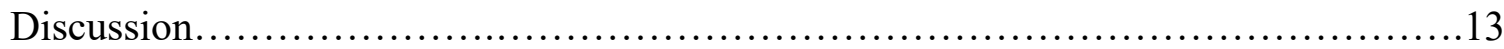

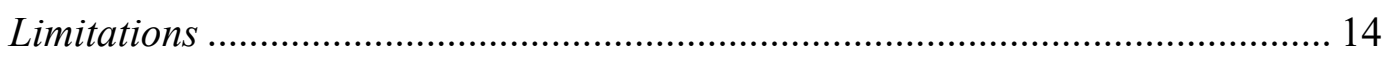

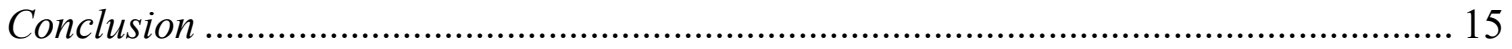

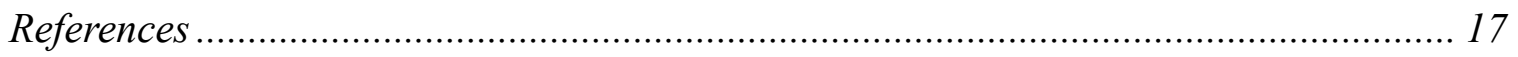

Tables................................................................... 22

Figures................................................................. 27

Appendices.............................................................. 
The Relationship Between Social Skills and Problem Behaviors in Adolescent Males with

\section{Autism Spectrum Disorders}

Individuals with autism spectrum disorders demonstrate difficulty with communication and social interactions and often display problem behaviors (National Institute of Mental Health Information Resource Center, 2018). Challenges with communication and social skill deficits increase the likelihood that individuals with autism will display antisocial behaviors (Shea, Payne, \& Russo, 2018). These behaviors often minimize access to the least restrictive setting in schools and prevent participation in extracurricular activities with peers (Simpson, de Boer-Ott, \& Myles, 2003). Verbal or physical aggression, conduct problems, self-injury, interrupting others, and rule-breaking are typical behaviors that occur more commonly in adolescents with autism when compared to their same-aged peers (Shea et al., 2018; Volker et al., 2010). Problem behaviors are a result of comorbid issues such as lower cognitive functioning, problems sleeping, and difficulty with focus; however, the presence of problem behaviors is not a direct symptom of autism (Hill et al., 2014; Shea et al., 2018). Social skills and problem behaviors are inter-related in individuals with autism; therefore, it is beneficial to have one evidence-based intervention that will positively affect both of these factors of concern. Studies provide evidence that if we can decrease problem behaviors for individuals with autism, as well as increase their social abilities, there are opportunities to positively impact their quality of life and secondary options (Carter et al., 2013).

\section{Social Skills Training}

Social skills training has been documented as an evidenced-based practice that influences social skills and problem behaviors for individuals with autism ages 1-14 years (Cotugno, 2009; Stichter et al., 2010; Wong et al., 2014). Social skills training consists of individual or group 
implemented instructional intervention that teaches learners with autism effective skills for communication, play, or social interaction (Bellini \& Peters, 2008; Wong et al., 2014). Selecting a program to implement social skills training can be a daunting process, as there are so many options available. McConnell (2002) identifies the essential components of a high-caliber social skills training program, which makes the program comprehensive, therefore more effective at improving social abilities for individuals with autism. According to McConnell (2002), a social skills training program is considered comprehensive when it combines two or more of the following strategies: environmental modifications, child-specific interventions, collateral skills interventions, or peer-mediated interventions. Collateral skills encourage individuals with autism to participate socially with typically developing peers. Child-specific interventions include the use of instructions, training, reinforcement, and generalization to increase social behaviors of individuals with autism. When combined, they meet criteria for a comprehensive program.

To ensure program effectiveness and the ability to select outcome measures, program alignment between assessment and intervention is critical but is rare within social skills training programs (Gresham, Sugai, \& Horner, 2001). In an evaluation of five different peer-reviewed social skills training programs, including PEERS, Children's Friendship Training, summerMAX, SENSE Theatre, and a Cognitive Behavioral Therapy program aimed at teaching social skills to individuals with autism Wolstencroft et al. (2018) reported that no programs involved an assessment aligned with skills instruction. These programs meet criteria as comprehensive (McConnell, 2002), although they are varied according to their mode of delivery and social behavior targets (Wolstencroft et al., 2018). Similar to the social skills training programs reviewed by Wolstencroft et al. (2018), Coucouvanis (2005) developed Super Skills: A Social Skills Group Program for Children with Asperger Syndrome, High-Functioning Autism and 
Related Challenges .Super Skills is a comprehensive program that includes collateral skill interventions and child-specific interventions. A major strength of the Super Skills program is the assessment component, which aligns with the skills taught in the Super Skills lessons. The Super Skills program involves an assessment (i.e., the Profile of Social Difficulty) specifically created to determine baseline levels of social functioning, guide selection of program activities within the Super Skills program, and determine skill acquisition.

\section{Purpose of this Study}

The purpose of this research was to determine if the implementation of a specific social skills training program, Super Skills developed by Coucouvanis (2005), can effectively increase social skills and decrease problem behaviors. This study included two primary goals. The first goal was to evaluate if the social skills training program, Super Skills, was an effective program for school-based social skills training. It was anticipated that the components of the Super Skills program would be associated with increased social skills. The second goal was to examine whether teaching social skills to adolescent boys who have autism would produce significant positive changes in problem behaviors. Evidence suggests that some problem behaviors can be prevented or reduced if social functioning is increased (Boyd, McDonough, \& Bodfish, 2012); one approach to heighten social functioning for students with autism involves specific social skills training. Although specific interventions to address problem behaviors were not explicitly addressed in this study, it was predicted that indirect influences on problem behaviors would manifest if social skills were directly impacted by social skills training (Barry et al., 2003; von der Embse, Brown, \& Fortain, 2011). 


\section{Method}

\section{Participants}

This study was approved by the [University name removed for blind review] Institutional Review Board. Parents granted consent through an IRB-approved parental permission form. Participants were recruited through a local middle school and included six middle school adolescent male students with autism and three middle school males without autism as peer models. The six boys with autism ranged in ages from 13 to 14 years, received the majority of their education in a self-contained classroom, and had an educational diagnosis of autism based on the local school division's criteria for eligibility for an Individualized Education Program. The special education teachers identified these six students as needing additional social skills instruction.

Social skills training was implemented in two sub-groups based on individual Social Responsiveness Scale-Second Edition (SRS-2) scores. Higher individual scores on SRS-2 indicate more significant social deficits, and a total score of 76 or higher is associated with severe autism (Wilkinson, 2016). Scores below 59 are not typically associated with autism. Participants with an SRS-2 Score within the range of 133-160 were assigned to Social Skills Training Group One (i.e., SST1), and students with an SRS score of 90-101 were assigned to Social Skills Training Group Two (i.e., SST2). The three male students without autism had SRS scores ranging from 19-27 and did not exhibit any social impairments or other characteristics of autism. Results of the SRS-2 indicated that the students in SST1 would likely require more assistance with social skills training; therefore, two of the three typically developing students were assigned to SST1. One typically developing student was placed with SST2. Table 1 presents the demographic information for all participants with autism. 


\section{Design}

The effect of the Super Skills program was analyzed in a group multiple baseline single subject design. The design involved two phases, baseline and implementation. Experimental control was demonstrated by repeating the measures, verifying the effect of the independent variable, and replication of control across participants (Carr, 2005; Kelly, 1980; Stokes \& Fawcett, 1977). Group training sessions were initiated following a five-day baseline for SST1 and a nine-day baseline for SST2. The intervention occurred over eight weeks for both groups. The participants' performance was assessed following each session to determine mastery and progression to the next skill. Acquisition of social skills was determined by examining the change in POSD scores from baseline to post-intervention. Changes in problem behaviors were evaluated using visual analyses of behavior data on a line graph and determining the level, trend, and variability.

\section{Measures}

\section{SRS-2 Teacher Rating Form, School Age Form}

The SRS-2 is a standardized 65-item teacher report questionnaire that measures the five subscale areas of social awareness, social cognition, social communication, social motivation, and restricted interests and repetitive behavior. The SRS-2 was administered to provide a confirmation of autism diagnosis and to assist in student groupings. Studies have shown that the SRS-2 demonstrates significant reliability when measuring characteristics of autism across severity and can identify social deficits related to autism (Duvekot, Ende, Verhulst, \& GreavesLord, 2015; Wilkinson, 2016). The tool has specific forms to address distinct age groups; this research used the school-age form. Some sample items from the SRS-2 School Age form are: is able to communicate his or her feelings to others, avoids eye contact or has unusual eye contact, 
recognizes when something is unfair, and is regarded by other children as dd or weird. The SRS2 School-Age Forms addresses students ages 4 to 18. The five treatment subscale areas are scored on a 4-point Likert scale from not true to almost always true. The sum of all subscale areas indicates the Total Score (T-score). The T-score indicates the autism severity level, 76 or higher is considered severe and associated with an autism diagnosis (Wilkinson, 2016). All participants with autism in this study had T-scores of 96 or higher scores are in Table 1.

\section{Profile of Social Difficulty (POSD)}

The POSD was administered as a pre-measure to determine specific deficits in social behavior and to guide activities to be taught from Super Skills. The POSD is an observation tool within the Super Skills Program; the results help to determine both target social behavior and lessons to implement within the Super Skills program. The POSD is a 59-item Likert scale teacher or parent questionnaire containing four subscale areas: Fundamental Skills, Social Initiation Skills, Social Response Skills, and Getting Along with Others (Coucouvanis, 2005). Subscale areas are those identified by Coucouvanis (2005) as social skills necessary for successful social interactions. Items from the POSD in the subscale areas include: Eye contact, Correct Facial Expression, Correct Voice Volume (Fundamental Skills); Using Person's Name, Getting, Asking for Help (Social Initiation Skills); Responding to Compliments, Listening, Following Directions (Social Response Skills); Taking Turns, Sharing, Playing by the Rules (Getting Along with Others). The four subscale areas are rated on a 6-point Likert scale from very difficult to very easy. The total score for each subscale area indicates the individual's abilities to demonstrate that skill. The sum of the subscale areas indicates their POSD score. POSD scores for the participants with autism are in Table 1. Antecedent Behavior Consequence (ABC) Narrative Recording 
$\mathrm{ABC}$ narrative recording is a descriptive assessment tool used to determine the contingencies that maintain behavior (Lanovaz, Argumedes, Roy, Duquette, \& Watkins, 2013; Matson \& Minshawi, 2007). The ABC form examines the: Antecedent (A) - what happens just before the behavior occurred; Behavior (B) - the behavior in observable terms; and, Consequence $(\mathrm{C})$ - determining the actions peers and others in the environment model as a response to the behavior of measure (Lanovaz et al., 2013).

\section{Frequency Recording Sheet}

The Frequency Recording Sheet uses event recording to record each occurrence of the behavior of interest. Event recording is common when behaviors can easily be counted and occur at low frequencies (Cooper, Heron, \& Heward, 2007). Data collection includes using a tally mark to document the occurrence of behavior and summing the total occurrences. 


\section{Procedure}

Social skills training was conducted once a week over eight weeks during the student's regularly scheduled school day. The implementation of the social skills training groups followed procedures outlined by Collet-Klingenberg (2009) as follows: (1) Identifying Social Skills Targeted for Instruction; (2) Organizing Training Groups; (3) Collecting Baseline Data; (4) Scheduling Group Meetings; (5) Creating a Training Format or Structure; (6) Organizing Topics for Instruction; (7) Specifying Embedded Instructional Strategies or Materials; (8) Training Helpers Prior to Implementing Group Instruction; (9) Implementing Social Skills Group Training; and, (10) Collecting Data on Target Behavior/Skills to Inform Instruction. Details regarding each step are provided in Appendix E. These steps were used in conjunction with the guidelines and activities from the Super Skills program (Coucouvanis, 2005).

Super Skills emphasizes four pro-social areas: fundamental skills, social initiation skills, social response skills, and getting along with others (Coucouvanis, 2005). Based on conversations and anecdotal data collected from teachers, social skills training sessions focused on fundamental skills and social initiation skills. Specific skills in the fundamental and social initiation pro-social areas can be found in Table 3. Participants were placed into groups based on SRS-2 scores as described in the Participants section above. There were 3-4 participants in each social skills training group following recommendations by Collet-Klingenberg (2009). The social skills training occurred in a special education classroom in an adjoining lounge area. The typically developing students joined the group for the 60-minute weekly lessons.

An $\mathrm{ABC}$ narrative recording form was used to collect baseline data for a problem behavior for each student with autism before implementing social skills training. The classroom teacher selected a problem behavior of concern that interfered with the student's daily routine. 
Teachers observed the students and recorded antecedents and consequences of the target problem behavior. The ABC Narrative recording form also allowed a function of the behavior to be determined upon implementation of social skills training, a frequency recoding form was used to document daily occurrences of problem behaviors. Daily occurrences of problem behaviors were tallied to determine whether the number of times the behavior occurred either increased or decreased.

Baseline social deficits were evaluated using the SRS-2 and the POSD. During baseline assessment, the special education teacher and paraprofessionals working in each classroom completed the POSD for each student. The average POSD score for each student was calculated based on the teacher and paraprofessionals scores. Appendix B contains a copy of the POSD. The lead teacher for each participant with autism rated the participants using the SRS-2. Subscale results were calculated and used in the determination of groupings for social skills training.

Upon the determination of the two social skills groups, the schedule of meetings was created based on student availability. Meetings occurred for eight weeks, on alternating Tuesdays or Wednesdays during the $2^{\text {nd }}$ block of the student's school day for 60 minutes per session.

Coucouvanis provided written permission for the use of the Super Skills program to instruct and assess the participants. Weekly sessions followed the structure outlined in the Super Skills program: welcome, greeting and introducing self, a practice of the previous weeks' skills, instruction of new skills, practicing of new skills, structured break, and review of new skills.

Topics for instruction are listed in Table 3. These were assessed in the POSD baseline assessment and were the topics addressed during the Super Skills lessons. Super Skills offers 30 lessons in the program. Coucouvanis (2005) indicated that lessons are not to be completed in sequential order but are to be selected based on student need. Therefore, for this research, lessons 
were not completed in sequential order but completed based on the skills deficits of the students in each group, as indicated by POSD scores. Simple skills were taught first and then more complex skills. Table 4 shows the weekly sequence of skills taught. A sample lesson from Super Skills can be found in Appendix C.

Super Skills recommends the use of games to facilitate conversations and allow the practice of skills such as turn taking. For this research, Gold Fish, Hungry Hungry Hippos, Table Topics, Matching, and Memory were all used to provide activities that required social interactions. Instructional strategies included the use of visual supports and peer-mediated instruction. Super Skills has visual supports embedded in the program that include pictures of instructions and activities to assist the students in comprehending the lessons. Visual supports were used for all sessions. Within peer-mediated instruction it is important to systematically teach typically developing peers how to engage with their peers with autism (Neitzel, 2008). This allows some peer-directed activities to be mixed with instructor directed activities. For this research, before training sessions, the social skills training facilitator reviewed social skills lesson and the session materials with the typically developing peers. Peers were also assigned specific duties to complete during the session.

Implementation of social skills group training followed the Creating a Training Format or Structure section as outlined by Collet-Klingenberg (2009). During the social skills training sessions, students with autism were reinforced when they exhibited a desired social skill. For example, when teaching them to say their name in a greeting, if a student correctly stated their name, they would immediately receive a "high-five" or a verbal "nice job saying your name". If the participant exhibited an incorrectly no response, the response was ignored, and the desired skill was retaught immediately. 
The occurrence of physical problem behaviors of hitting, throwing items, or walking away was either ignored or interrupted. For example, if a student threw a marble from the Hungry Hungry Hippo game, the behavior was ignored, someone from the group returned the marble to the game, and the group continued to play Hungry Hungry Hippo without acknowledging the problem behavior of throwing the marble.

Throughout implementation, as students demonstrated target social skills outlined in Table 2, a check mark would be placed beside the skill on the student's POSD. After the eightweek intervention, the teachers and paraprofessionals completed a POSD as a post-intervention measure.

The target problem behavior for each student was captured on a Frequency Recording Sheet. Subsequently, the daily frequency of the problem behaviors for each participant was entered into an Excel spreadsheet and patterns in behavior was graphed for visual analysis.

\section{Results}

\section{Social Skills}

Change in POSD scores was calculated by comparing baseline POSD scores to postimplementation POSD scores. Changes in scores are listed in Table 1. While small sample size $(N=6)$ prohibited statistical power to detect improvements, all participants increased in social skills. Participants in SST1 made more modest gains in social skills than their peers in SST2.

\section{Problem Behavior}

Visual analysis is a systematic method for assessing outcomes in a single subject design (Cooper, Heron, \& Heward, 2007; Ledford, Lane, \& Severini, 2018). Trend, level, and variability are used to describe patterns in data. Figure 1 displays the frequency of participants' problem behaviors including trend lines for baseline and intervention. There was not a consistent 
change in trend for participants in SST1 or SST2 from baseline to intervention. The level is the average value per phase. A change in level indicates a difference between intervention and baseline. Figure 2 displays the frequency of problem behavior with level indicated.

A complete list of student problem behaviors and the function of the problem behavior is presented in Table 2. A Sample ABC Data sheet is found in Appendix D. Participants in both groups experienced a change in level from baseline to intervention. The direction of the level change was variable, and there was no clear or consistent cause of this variability. Problem behaviors exhibited by participants in SST1 caused some of the implementation sessions to take longer than the initial 60-minutes allotted. In contrast, SST2 moved through the skills quickly and with less interruption during instruction.

Increases in Problem Behaviors. Participant 101 displayed an increasing trend from baseline to intervention in his problem behavior of head hitting with a function of sensory. Similarly, participant 202 increased his problem behavior that involved interrupting with a function of escape. For participant 101, there was a tight relationship between sensory and escape as the function of his behavior. Participant 202 constantly interrupted sessions by requesting to go to the bathroom, to engage in a different activity, and to see a different staff person. These escape-maintained behaviors increased for the same reason as participant 101's head hitting behavior. There were more demands on the participants and hence a greater need to exhibit the problem behavior in an attempt to escape social skills training.

Decreases in Problem Behaviors. During the intervention, decreased problem behaviors of whining, loud vocalizations, and verbal outburst with a function of attention were demonstrated by participants 102, 201, and 203, respectively. Participant 103's problem behavior of falling asleep with a function of escape also decreased during the intervention. Participants 
102, 201, and 203 reductions in problem behavior provide an indication that social skills training supplied additional attention that they were seeking through the use of problem behaviors. This is also reflective of the level of participation of 102, 201, and 203.

\section{Discussion}

Increasing social abilities for an individual with autism takes practice and application in diverse settings and with different people. Enhanced social abilities have the potential to positively affect other dimensions of an individual's life, including the reduction in problem behaviors. There was some initial concern that participants with greater social deficits may not acquire new skills at the same rate of their peers during the 8-week intervention. This concern was addressed by the use of the groupings for social skills training. Because students were grouped with peers who had similar SRS-2 scores, their initial social functioning was similar, and skills taught through the Super Skills program were comparable. This is important to note because implementing social skills training in a group does not mean that everyone in the group will necessarily achieve the same social abilities. But it does ensure that they will learn from each other, and ultimately this maximizes the likelihood that all individuals will improve when compared to baseline levels.

Results from this study indicate that social skills training for individuals with autism can lead to increased social skills as measured by the POSD. Overall, all skills listed in Table 4 increased across all students. If maintained, improvements in these skills may increase social opportunities and enhance social relationships. These skills should be generalized to various settings and be reinforced through natural contingencies.

Although Wong et al. (2014) indicated social skills training groups are an evidence-based practice for behavior change and social skills training, the function of the behavior must be taken 
into account when implementing the intervention. For this research, the social skills training did not attempt to address the function of the problem behavior directly. The goal was to address social deficits and determine if there was an indirect influence on problem behaviors. Contrary to initial predictions, social skills training did not demonstrate a consistent effect on problem behaviors. The implications of social skills training on problem behavior varied amongst individuals within each group. This was verification that the use of function-based interventions is essential. There was preliminary evidence that social skills training may indirectly influence problem behaviors with a function of attention.

\section{Limitations}

The Super Skills program is an intervention package with several layered components. The program is not manualized, so activities are not standard and differ slightly between groups. Therefore, it is difficult to isolate the influence of particular factors in changing behavior (Kelly, 1980). This has the advantage of allowing the program to be broadly applicable and flexible but impedes evaluation of fidelity of implementation for replication.

Controlling for environmental changes and antecedent events was impossible. These factors can have a significant impact on students with autism and could significantly influence the occurrence of problem behaviors and social skills; ultimately this may compromise a demonstration of experimental control (Smith \& Iwata, 1997). For example, during week six's meeting with SST1, there was a fire drill. The drill interrupted the lesson and terminated the meeting. Also, throughout the 8-week intervention, student 101 attempted to bite or squeeze student 102 during social skills training sessions. These problem behaviors caused distraction and increased the number of trials necessary for participants to master new skills. Environmental 
events such as these cannot be controlled in naturalistic classroom interventions nor was their impact adequately captured and accounted for analytically.

The POSD is not a validated measure, so the SRS-2 was used as an additional measure of social deficits. Because SRS-2 is not directly aligned with the Super Skills program, the POSD was necessary to assess specific skills taught through Super Skills. Baseline subscale area scores of Fundamental Skills and Social Initiation Skills from the POSD were compared to the Social Communication Subscale scores from the SRS-2 to determine the validity of the POSD. Based on this, there was alignment between baseline POSD scores and SRS-2 scores demonstrating preliminary evidence that the POSD is an effective measure of social deficits for individuals with autism.

\section{Conclusion}

Teaching social skills to a student with autism is not a new concept. There is considerable research that spans decades of inquiry on the importance of teaching social skills to students with autism. For this research, the goal was to focus specifically on possible indirect impacts on problem behavior of teaching social skills to students with autism. This research provided preliminary evidence of a positive impact of social skills training on social skills as an intervention for adolescent males with autism. Unfortunately, there was not a consistent impact on problem behaviors. Problem behaviors with a function of attention decreased, problem behaviors with a function of escape were inconsistent, and problem behaviors with a function of sensory stimulation increased during the intervention. Taken together, this study indicated moderate evidence for the use of Super Skills to increase social skills and to decrease problem behaviors motivated by attention. 
The initial evidence that there is an impact on problem behaviors with a function of attention brings attention to the importance of determining the function of problem behaviors and the need to teach functionally equivalent replacement behaviors for problem behaviors. Social skills training groups should be fun and reinforcing for the participants. Social skill training groups are a perfect time to offer participants who have a high need for peer or staff attention the attention they desire, while also teaching them appropriate methods for requesting attention from their peers.

An additional interest was to bring applicable theory to practice for teachers who want to teach social skills to students with autism through the use of a cost-effective and comprehensive social skills program. The Super Skills program was selected for this reason. The program allowed for social skills to be assessed and taught practically. The Super Skills' flexibility and ease of implementation could be particularly beneficial to classroom teachers who serve students with different social abilities as well as different educational accommodation needs. 


\section{References}

Barry, T. D., Klinger, L. G., Lee, J. M., Palardy, N., Gilmore, T., \& Bodin, S. D. (2003). Examining the effectiveness of an outpatient clinic-based social skills group for high-functioning children with autism. Journal of Autism and Developmental Disorders, 33, 685-701. doi:10.1023/B:JADD.0000006004.86556.e0

Bellini, S., \& Peters, J. K. (2008). Social skills training for youth with autism spectrum disorders. Child and Adolescent Psychiatric Clinics of North America, 17, 857-873. doi:10.1016/j.chc.2008.06.008

Boyd, B. A., McDonough, S. G., \& Bodfish, J. W. (2012). Evidence-based behavioral interventions for repetitive behaviors in autism. Journal of Autism and Developmental Disorders, 42, 1236-1248. doi:10.1007/s10803-011-1284-z

Bruni, T. P. (2014). Test review: Social Responsiveness Scale-Second Edition (SRS-2). Journal of Psychoeducational Assessment, 32, 365-369. doi:10.1177/0734282913517525

Carr, J. E. (2005). Recommendations for reporting multiple-baseline designs across participants. Behavioral Interventions, 20, 219-224. doi:10.1002/bin.191

Carter, E. W., Common, E. A., Sreckovic, M. A., Huber, H. B., Bottema-Beutel, K., Gustafson, J. R., Hume, K. (2013). Promoting social competence and peer relationships for adolescents with autism spectrum disorders. Remedial and Special Education, 35, 91-101. doi: $10.1177 / 0741932513514618$

Collet-Klingenberg, L. (2009). Overview of social skills groups. Madison, WI: The National Professional Development Center on Autism Spectrum Disorders, Waisman Center, University of Wisconsin.

Cooper, J. O., Heron, T. E., \& Heward, W. L. (2007). Applied behavior analysis (Vol. 2). Upper 


\section{Saddle River, NJ: Pearson/Merrill-Prentice Hall.}

Cotugno, A. J. (2009). Social competence and social skills training and intervention for children with Autism Spectrum Disorders. Journal of Autism and Developmental Disorders, 39, 1268-1277. doi:10.1007/s10803-009-0741-4

Coucouvanis, J. (2005). Super skills: A social skills group program for children with asperger syndrome, high-functioning autism and related disorders. Shawnee Mission, KS: Autism Asperger Publishing Co. doi:10.1109/TAC.2017.2744499

Duvekot, J., Ende, J., Verhulst, F., \& Greaves-Lord, K. (2015). The screening accuracy of the parent and teacher-reported Social Responsiveness Scale (SRS): Comparison with the 3Di and ADOS. Journal of Autism \& Developmental Disorders, 45, 1658-1672. doi:10.0.3.239/s 10803-014-2323-3

Gresham, F. M., Sugai, G., \& Horner, R. H. (2001). Interpreting outcomes of social skills training for students with high-incidence disabilities. Exceptional Children, 67, 331-344.

Hill, A. P., Zuckerman, K. E., Hagen, A. D., Kriz, D. J., Duvall, S. W., van Santen, J., Fombonne, E. (2014). Aggressive behavior problems in children with autism spectrum disorders: Prevalence and correlates in a large clinical sample. Research in Autism Spectrum Disorders, 8, 1121-1133. doi:10.1016/j.rasd.2014.05.006

Kelly, J. A. (1980). The simultaneous replication design: The use of a multiple baseline to establish experimental control in single group social skills treatment studies. Journal of Behavior Therapy and Experimental Psychiatry, 11, 203-207. doi:10.1016/0005-7916(80)90028-2

Lanovaz, M. J., Argumedes, M., Roy, D., Duquette, J. R., \& Watkins, N. (2013). Using ABC narrative recording to identify the function of problem behavior: A pilot study. Research in Developmental Disabilities, 34, 2734-2742. doi:10.1016/j.ridd.2013.05.038 
Ledford, J. R., Lane, J. D., \& Severini, K. E. (2018). Systematic use of visual analysis for assessing outcomes in single case design studies. Brain Impairment, 19, 4-17. doi:10.1017/BrImp.2017.16

Matson, J. L., \& Minshawi, N. F. (2007). Functional assessment of challenging behavior: Toward a strategy for applied settings. Research in Developmental Disabilities, 28, 353-361. doi:10.1016/j.ridd.2006.01.005

McConnell, S. R. (2002). Interventions to facilitate social interaction for young children with autism: Review of available research and recommendations for educational intervention and future research. Journal of Autism and Developmental Disorders, 32, 351-372. doi:10.1023/A:1020537805154

National Institute of Mental Health Information Resource Center. (2018). Autism Spectrum Disorder. Retrieved November 4, 2018, from https://www.nimh.nih.gov/health/topics/autism-spectrum-disorders-asd/index.shtml Neitzel, J. (2008). Overview of peer-mediated instruction and intervention for children and youth with autism spectrum disorders. Chapel Hill, NC: National Professional Development Center on Autism Spectrum Disorders, Frank Porter Graham Child Development Institute, The University of North Carolina.

Shea, N., Payne, E., \& Russo, N. (2018). Brief report: Social functioning predicts externalizing problem behaviors in autism spectrum disorder. Journal of Autism and Developmental Disorders, 48, 2237-2242. doi:10.1007/s10803-017-3459-8

Simpson, R., de Boer-Ott, S., \& Myles, B. (2003). Inclusion of learners with autism spectrum disorders in general education settings. Topics in Language Disorders, 23, 116-133. doi:10.1097/00011363-200304000-00005 
Smith, R. G., \& Iwata, B. A. (1997). Antecedent influences on behavior disorders. Journal of Applied Behavior Analysis, 30, 343-375. doi:10.1901/jaba.1997.30-343

Stichter, J. P., Herzog, M. J., Visovsky, K., Schmidt, C., Randolph, J., Schultz, T., \& Gage, N. (2010). Social competence intervention for youth with asperger syndrome and highfunctioning autism: An initial investigation. Journal of Autism and Developmental Disorders, 40, 1067-1079. doi:10.1007/s10803-010-0959-1

Stokes, T. F., \& Fawcett, S. B. (1977). Evaluating municipal policy: An analysis of a refuse packaging program. Journal of Applied Behavior Analysis, 10, 391-398. doi:10.1901/jaba.1977.10-391

Tse, J., Strulovitch, J., Tagalakis, V., Meng, L., \& Fombonne, E. (2007). Social skills training for adolescents with Asperger syndrome and high-functioning autism. Journal of Autism \& Developmental Disorders, 37, 1960-1968. doi:10.0.3.239/s10803-006-0343-3

Volker, M. A., Lopata, C., Smerbeck, A. M., Knoll, V. A., Thomeer, M. L., Toomey, J. A., \& Rodgers, J. D. (2010). BASC-2 PRS profiles for students with high-functioning autism spectrum disorders. Journal of Autism \& Developmental Disorders, 40, 188-199. doi:10.0.3.239/s 10803-009-0849-6

von der Embse, N., Brown, A., \& Fortain, J. (2011). Facilitating inclusion by reducing problem behaviors for students with autism spectrum disorders. Intervention in School and Clinic, 47,22-30. doi:10.1177/1053451211406545

Wilkinson, L. T. (2016). A best practice guide to assessment and intervention for autism spectrum disorder in schools. London; Jessica Kingsley Publishers.

Williams-White, S., Keonig, K., \& Scahill, L. (2007). Social skills development in children with autism spectrum disorders: a review of the intervention research. Journal of Autism and 
Developmental Disorders, 37, 1858-1868. doi:10.1007/s10803-006-0320-х

Wolstencroft, J., Robinson, L., Srinivasan, R., Kerry, E., Mandy, W., \& Skuse, D. (2018). A systematic review of group social skills interventions, and meta-analysis of outcomes, for children with high functioning asd. Journal of Autism and Developmental Disorders, 48, 2293-2307. doi:10.1007/s10803-018-3485-1

Wong, C., Odom, S. L., Hume, K., Cox, A. W., Fettig, A., Kucharczyk, S., \& Schultz, T. R. (2014). Evidence-based practices for children, youth, and young adults with autism spectrum disorder. Retrieved from http://autismpdc.fpg.unc.edu/sites/autismpdc.fpg.unc.edu/files/2014-EBP-Report.pdf 
Table 1

Demographics and Baseline Social Skills of Participants

\begin{tabular}{|c|c|c|c|c|c|}
\hline \multirow[t]{5}{*}{ Participant } & Age & Social & Baseline & Post Profile & Increase in \\
\hline & & Responsiven & Profile of & of Social & Score of \\
\hline & & ess Scale-2 & Social & Difficulty & Profile of \\
\hline & & T-Score & Difficulty & Scores & Social \\
\hline & & & Scores & & Difficulty \\
\hline \multicolumn{6}{|c|}{ Participants with Autism } \\
\hline 101 & 13 & 133 & 55 & 71 & 16 \\
\hline 102 & 13 & 160 & 15 & 26 & 11 \\
\hline 103 & 13 & 142 & 62 & 76 & 14 \\
\hline 201 & 14 & 90 & 30 & 69 & 39 \\
\hline 202 & 14 & 101 & 93 & 124 & 31 \\
\hline 203 & 13 & 93 & 33 & 66 & 33 \\
\hline
\end{tabular}


Table 2

Target problem behavior and function of the problem behavior

\begin{tabular}{lll}
\hline Participant & Problem Behavior & Function of the Problem \\
& & Behavior \\
\hline 101 & Head Hitting & Sensory \\
102 & Whining & Attention \\
103 & Falling Asleep & Escape \\
201 & Loud Vocalization & Attention \\
202 & Interrupting & Escape \\
203 & Verbal Outburst & Attention \\
\hline
\end{tabular}


Table 3

Social skills taught during social skills instruction

Fundamental Skills

1 Eye Contact

2 Correct Facial Expression

3 Correct Voice Volume

4 Correct Voice Tone

$5 \quad$ Correct Timing

Social Initiation Skills

6 Using Person's Name

$7 \quad$ Using Farewells

$8 \quad$ Greeting

9 Introducing Self

10 Asking for Help

11 Giving a Compliment

12 Starting a Conversation

13 Entering a Conversation

14 Ending a Conversation

15 Exchanging Conversation

16 Inviting Someone to Play

17 Introducing Others

18 Joining In

19 Talking About Self 
20 Making a Complaint

21 Asking Appropriate Questions

22 Offering an Opinion

23 Expressing Basic Feelings

24 Expressing Complex Feelings 
Table 4

Weekly Social Skills Taught to Social Skills Training Groups

Skills Taught to Social Skills Training Skills Taught to Social Skills Training

Week Group 1

Group 2

$1 \quad$ Greeting, Introducing Self

Greeting, Introducing Self

2 Eye Contact, Correct Facial Expression

Eye Contact, Correct Facial Expression

3 Correct Voice Volume, Correct Voice

Correct Voice Volume, Correct Voice Tone

Tone, Using a Person's Name

4 Correct Voice Volume, Correct Voice

Giving a Compliment, Starting a

Tone, Using a Person's Name

Conversation, Ending a conversation

5 Correct Voice Volume, Correct Voice

Giving a Compliment, Starting a

Tone, Using a Person's Name

Conversation, Ending a conversation

6 Using a Person's Name, Using Farewells

Exchanging a conversation, Inviting someone to play

$7 \quad$ Inviting Someone to Play

Exchanging a conversation, Inviting someone to play

8 Inviting Someone to Play

Exchanging a conversation, Inviting someone to play 


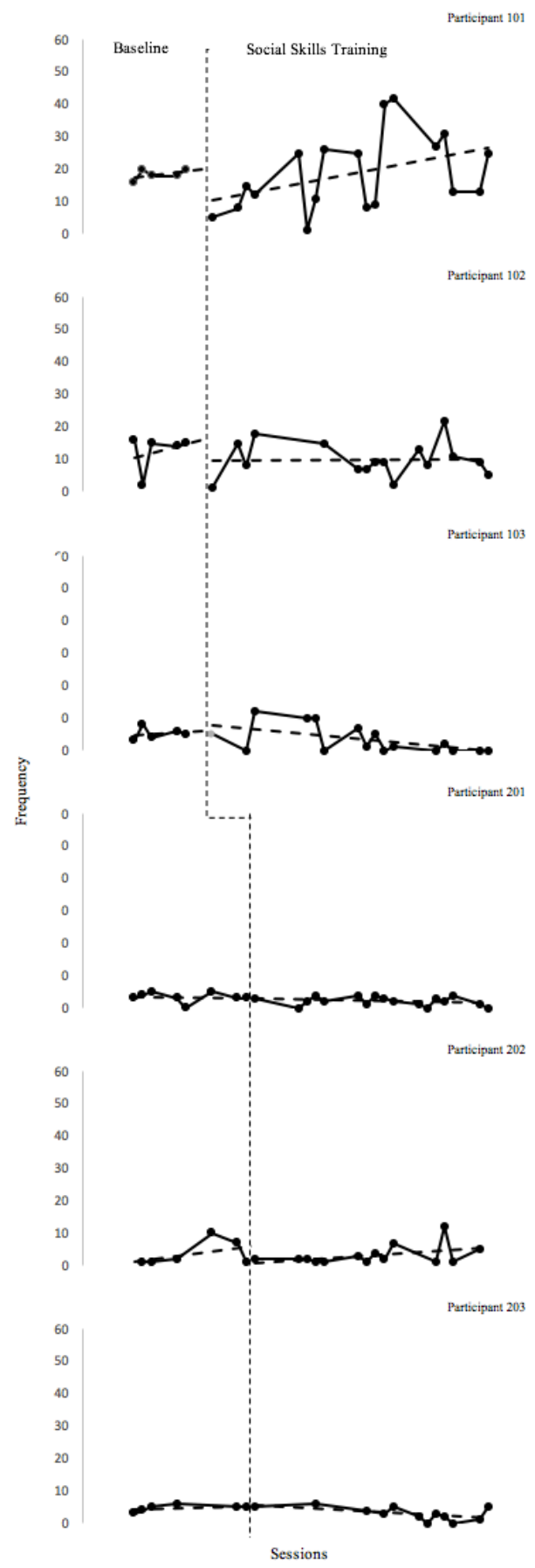

Figure 1. Frequency of problem behaviors with trendline for participants with autism in Social Skills Training Group 1 and Social Skills Training Group 2. 


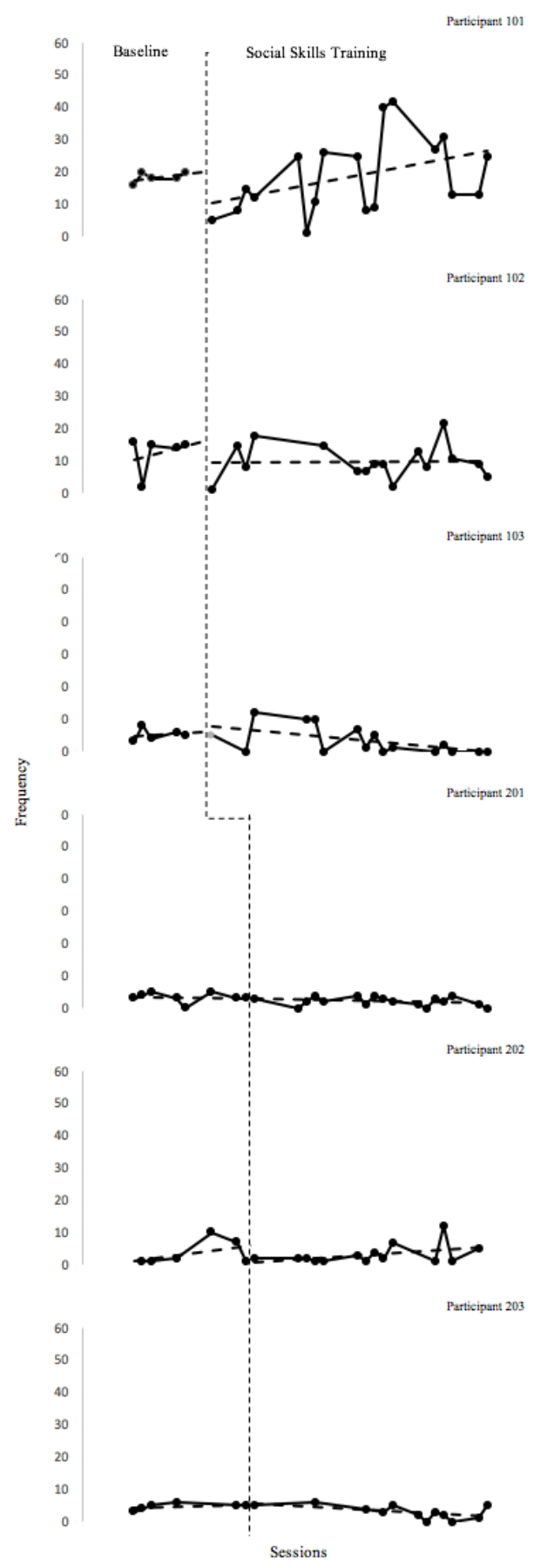




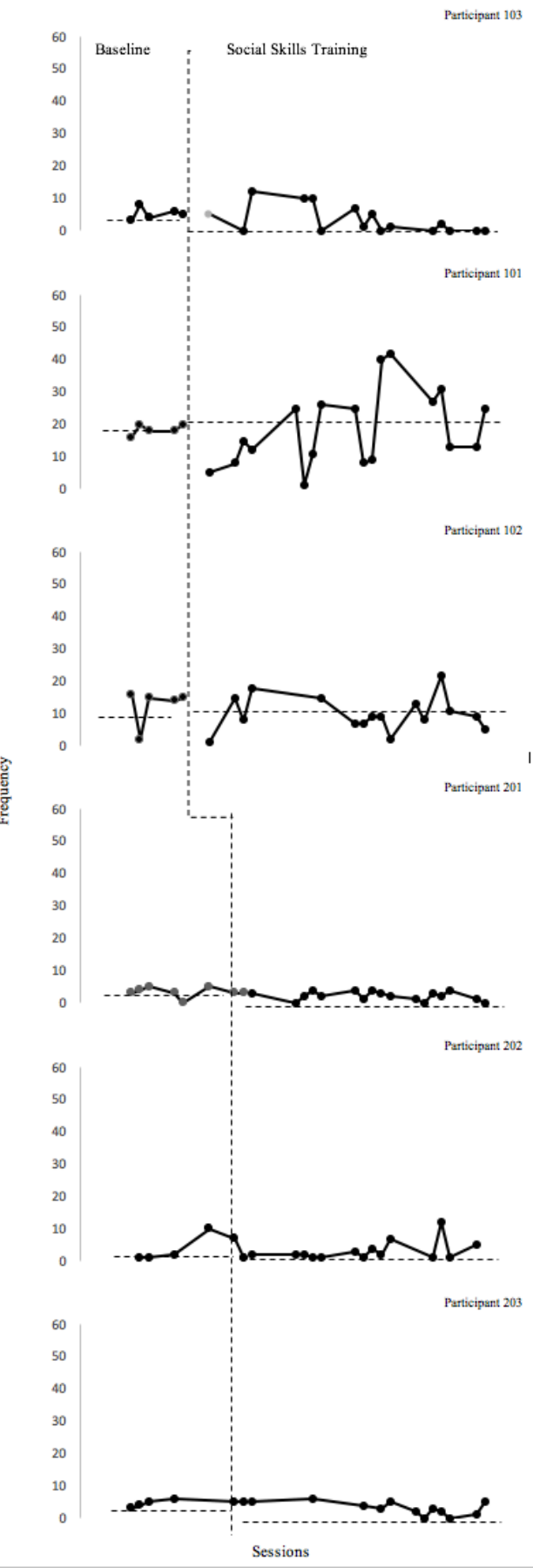

Figure 2. Frequency of problem behaviors with level for participants with autism in Social Skills Training Group 1 and Social Skills Training Group 2. 
Appendix A

Super Skills

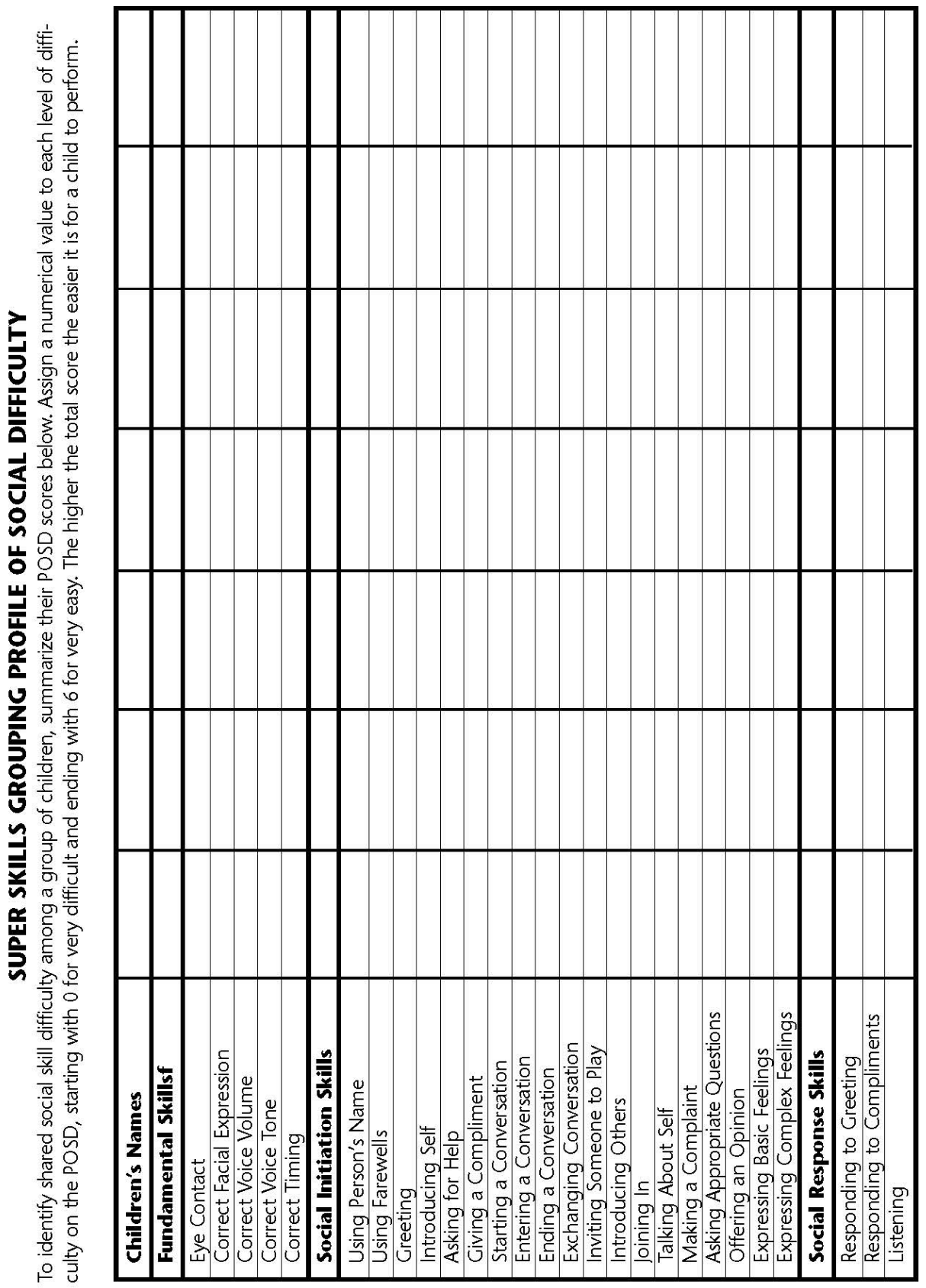


Appendix B

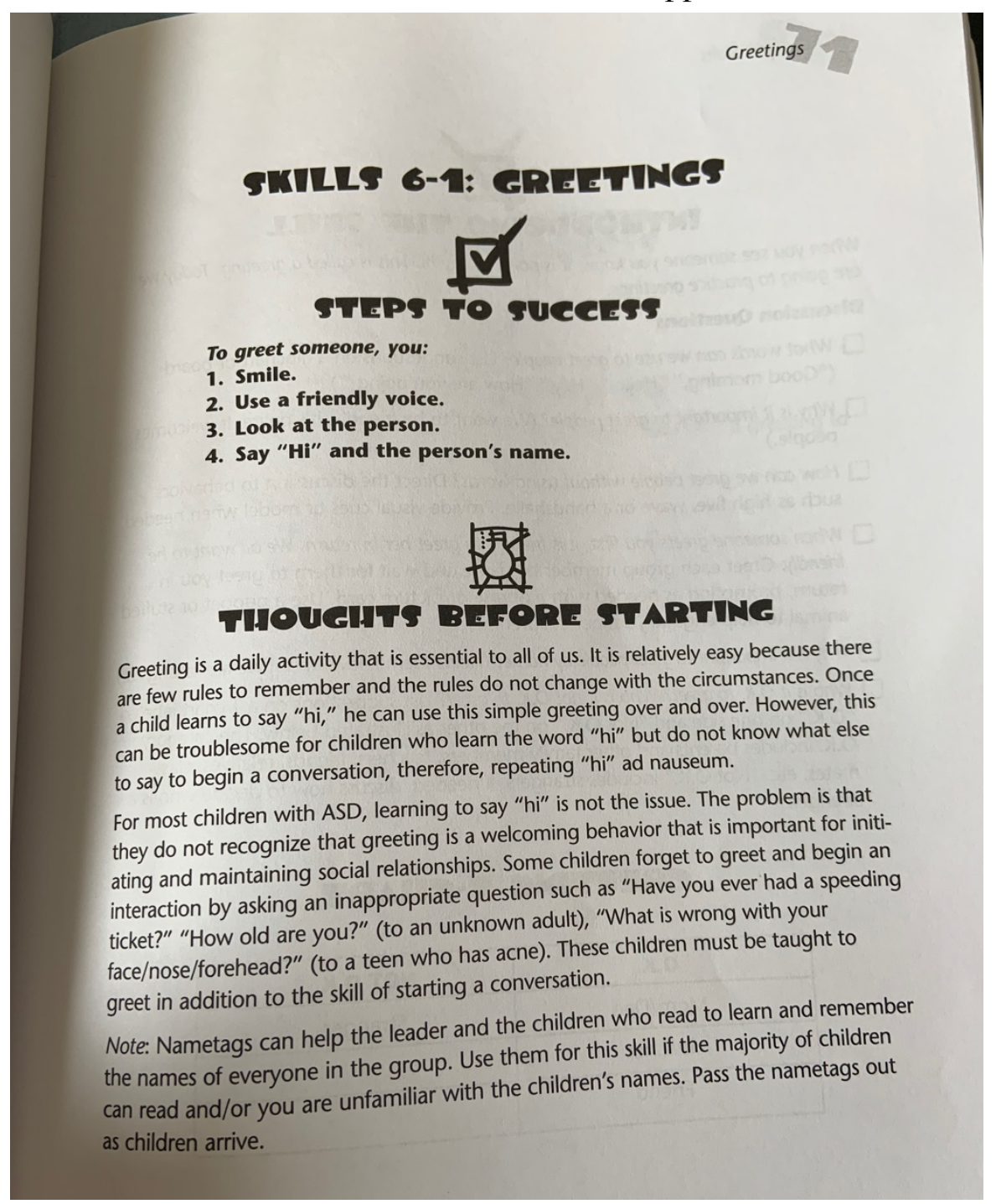




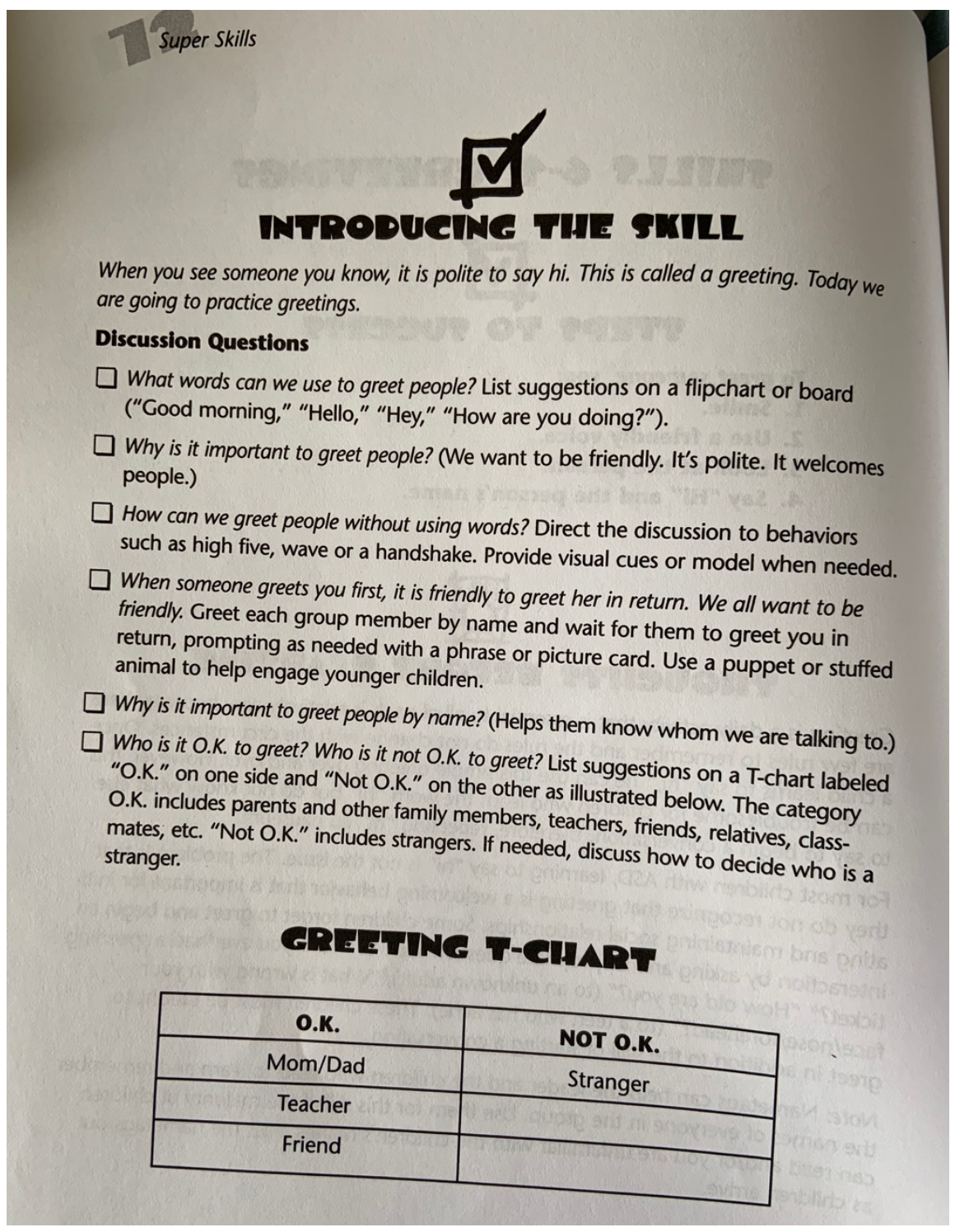



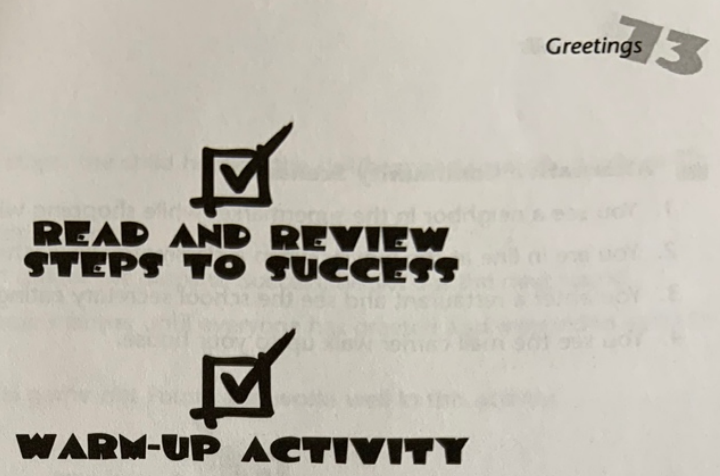

Direct the children to exit the room one at a time and re-enter with a greeting to the group. Peers respond with a return greeting.

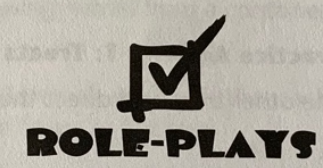

Review the role-play format presented in Chapter 5.

Ali. Alternative School Scenarios

1. You get on the bus. Greet the bus driver and the student you sit next to.

2. You enter the classroom. Greet your teacher and the child who sits behind you.

3. You see your older sister in the hall.

4. The principal greets you at recess.

\section{Alternative Home Scenarios}

1. Your grandmother comes to visit.

2. Your mother/father comes home.

3. The doorbell rings and you answer the door.

4. You are mowing the lawn and a neighbor walks by with her baby in a stroller. 


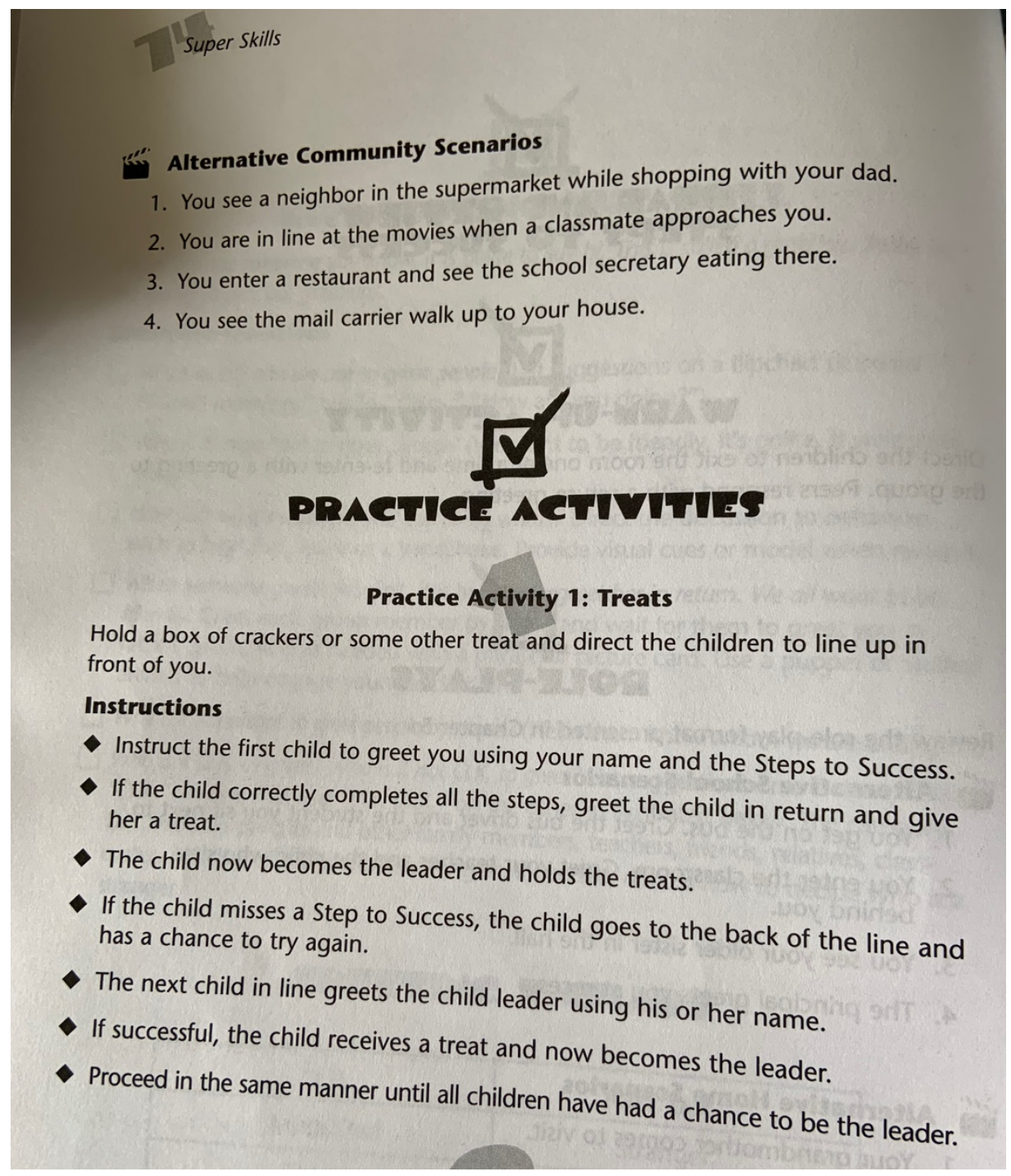


Appendix C

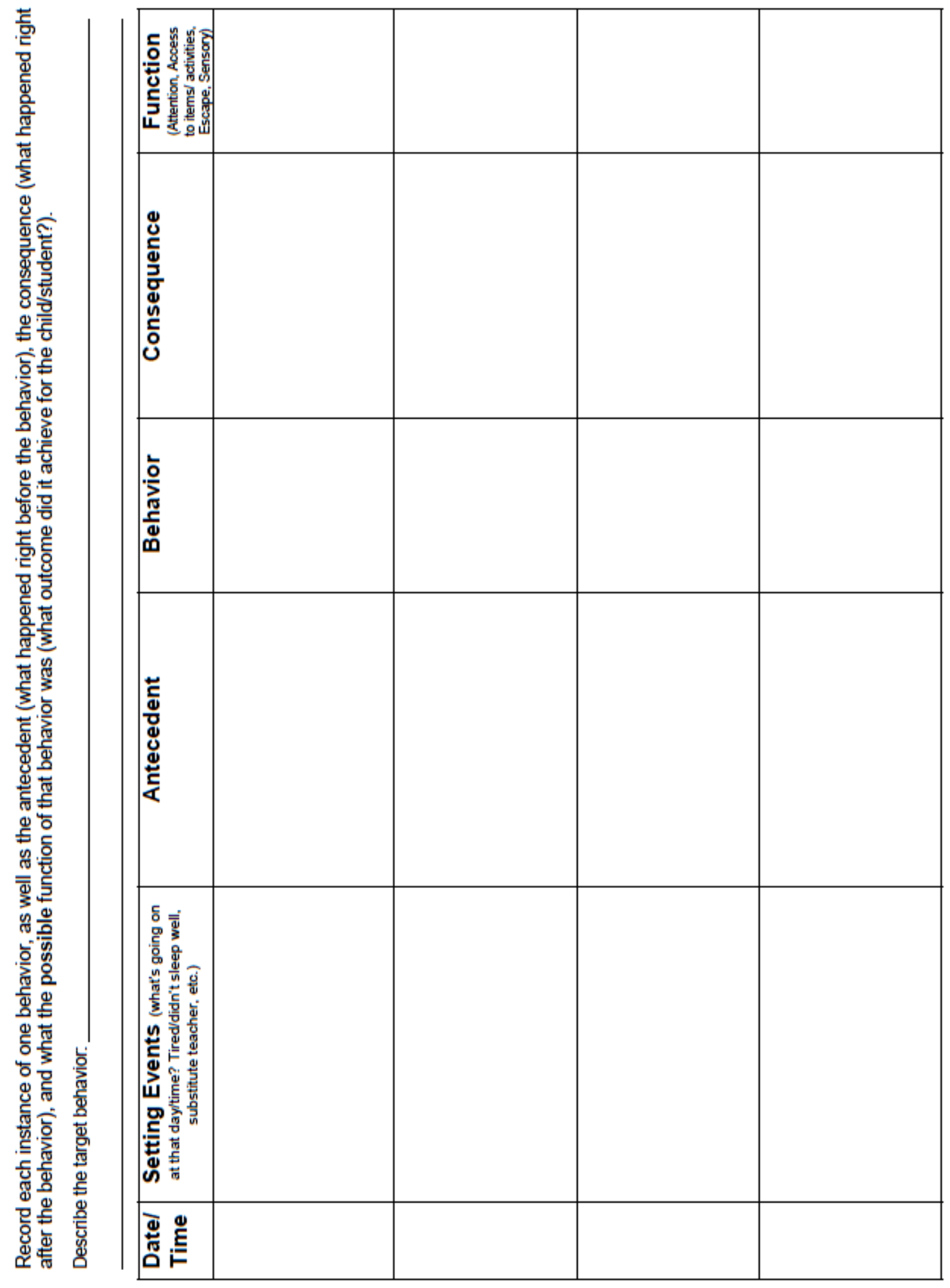




\section{Appendix D}

National Professional Development Center on Autism Spectrum Disorders

\section{Module: Social Skills Groups \\ Steps for Implementation: Social Skills Groups}

Collet-Klingenberg, L. (2009). Steps for implementation: Social skills groups. Madison, WI: The National Professional Development Center on Autism Spectrum Disorders, Waisman Center, University of Wisconsin.

Social skills groups may be used to teach a variety of social behaviors. In the evidence base, social skills group training targeted perspective-taking, conversation skills, friendship skills, problem-solving, social competence, emotion recognition, theory of mind, and problem-solving. In addition, specific interaction skills such as initiation, responding, maintaining, greeting, giving/accepting compliments, turn taking, sharing, asking for help, offering help, and including others were also improved through the use of social skills groups. The researchers who provided the evidence base for this practice approached group instruction in various ways, but all included several common components, outlined in the steps that follow. Most published social skills group curricula provide guidelines or implementation steps specific to the program that should be followed. The following steps are designed to help teachers/practitioners use existing resources to implement social skills group instruction that is based on informal needs assessment and data collection and on individual IEP/IFSP goals.

\section{Step 1. Identifying Social Skills Targeted for Instruction}

1. Teachers/practitioners refer to the IEP/IFSP to identify relevant goals for individual learners with ASD.

Often when the decision is made to implement social skills group instruction, skill deficits or social goals have already been identified for two or more learners with ASD. Before implementing social skills training groups, teachers/practitioners objectively define the target behaviors or skills that will be the focus of the intervention based on learners' IEP or IFSP goals.

2. Teachers/practitioners discuss goals with the IEP/IFSP team, including family members and learners.

Teachers/practitioners talk with the learners and with those who know the learners to determine how group skills could be targeted during instruction. For example, one learner may have trouble initiating verbal interactions with others. Another may have no trouble initiating, but usually does so in a way that alienates others (e.g., runs toward them yelling). A third may initiate, but does not wait for a response before moving on to someone else. Many social behaviors can be grouped for instruction. Conversation skills, for example, are made up of smaller skills or behaviors such as initiating, turn-taking, and terminating interactions. Learners with different skill levels and needs can be placed in the same group where they can model and practice the skills that they have, while at the same time learning new skills.

3. Teachers/practitioners ensure that the target of instruction is observable and measurable. 
National Professional Development Center on Autism Spectrum Disorders

\section{Module: Social Skills Groups}

Once relevant goals have been identified, and the goals of multiple learners have been grouped for instruction, teachers/practitioners write goals for the target behavior/skill that are observable and measurable. Using the example of conversation skills, it is not enough to write the goal simply as, "Joe, Tom, and Matt will improve their conversation skills." While those who know the boys well will have a general understanding of the goal, it does not provide enough detail for collecting reliable data or providing systematic instruction. A specific goal that becomes more easily observed and measured might be, "Joe, Tom, and Matt will improve their conversation skills in the following ways: Joe will increase conversational initiations by $50 \%$; Tom will initiate interactions with others using a calm voice and will stand still or sit during interactions; and Matt will wait for a count of ten, allowing his partner an opportunity to respond, before initiating a second time or with another person."

\section{Step 2. Organizing Training Groups}

1. Teachers/practitioners identify group members with similar goals.

Unlike peer-mediated instruction and intervention (please refer to the PMII resources developed by the National Professional Development Center on ASD at www.autisminternetmodules.org), social skills groups are typically made up only of learners with ASD or other disabilities. Though it may be tempting to include typically developing learners with limited social skills, the evidence base for this practice was based on learners with ASD. Students with ASD have unique social and communication characteristics that are often not evident in learners with other disabilities.

2. Teachers/practitioners select adults/helpers who have experience with ASD or who have received professional development about the needs of learners with ASD.

When selecting adult leaders or group facilitators, teachers/practitioners should be careful to employ only those who are familiar with the learners and/or have had experience working with learners with ASD. Group leaders may include teachers, psychologists, speech-language pathologists, educational assistants, parents, or others who have previously worked with some or all of the learners. Many high schools, however, use upper classmen to tutor or otherwise support younger learners (with and without disabilities). This is an acceptable alternative if qualified adults are not available to assist with social skills group instruction. If peers assist with social groups, they should be given an overview of ASD and introduced to the learners in the social skills group (with parental permission, of course) prior to beginning the group instruction. This introduction to ASD and to the students in the social skills group will provide an opportunity for any questions or concerns to be addressed prior to beginning training.

3. Teachers/practitioners organize groups that contain no more than three or four learners per adult/helper.

Ideally, one leader or assistant for every three learners should be involved in training. Depending on the needs and characteristics of the learners, more or fewer helpers may be appropriate. In the evidence-based studies, groups ranged from three to nine members, with most having four per group. 
National Professional Development Center on Autism Spectrum Disorders

\section{Module: Social Skills Groups}

\section{Step 3. Collecting Baseline Data}

1. Teachers/practitioners create data sheets using group members' individual target behaviors and goals.

Data sheets may vary by individual, or one data sheet that captures all students' target skills may be developed. For example, if the individuals participating in the social skills group are each working on different aspects of conversational skills, teachers/practitioners could design a data sheet that reflects all aspects of conversation (e.g., initiations, turn-taking, terminations, asking leading or follow-up questions, responding to others' initiations). On this same data sheet, teachers/practitioners could then collect data for individual learners that focus only on the specific skill that they are working on. (See sample data sheets attached to this document.)

2. Teachers/practitioners record data for each group member on the data sheet(s).

3. Teachers/practitioners collect, summarize, and graph sufficient data to identify learners' current use of skills.

Once baseline data have been collected for a sufficient amount of time (e.g., on at least three occasions), data should be summarized or graphed to document learners' current use of target skills and to provide a starting point for tracking learner progress.

\section{Step 4. Scheduling Group Meetings}

1. Teachers/practitioners select a time and place for holding training meetings that is mutually convenient and optimal for both learners and helpers.

Once the learners have been identified for social skills group instruction, and the adults who will lead and assist the group have been recruited, it is time to determine when the group training will take place. Social skill group training may occur during the regular instructional day, before or after school, during a lunch or recess/break time, or even on a weekend. When selecting the time for the training, consider the schedules of leaders and learners, as well as the characteristics of learners. For example, if missing the regularly scheduled lunch or recess is likely to lead to interfering behavior (e.g., increased stereotypic behaviors or aggression), then avoid scheduling a group session at that time. Similarly, if a learner is known to have trouble getting started in the morning, including him in an early morning social skills group may not result in the desired outcome.

2. Teachers/practitioners establish sufficient time for teaching, but not so long that learners become overwhelmed or lose interest.

The studies in the evidence base included training meetings that lasted from 10 to 90 minutes and included time for a warm up, instructional time, practice time, feedback, and ended with a snack or free time to reward those involved (as well as provide a safe setting for continued practice of the skills being learned). 
National Professional Development Center on Autism Spectrum Disorders

\section{Module: Social Skills Groups}

The number of training sessions and how often each group meets will vary by the topic or target of instruction and by how quickly progress is made in learning the skills. In the evidence-based studies, social skills training groups were implemented for a minimum of 12 sessions; however, some trainings lasted for as many as 20 sessions. Many of the groups in the studies met three or four times each week.

3. Teachers/practitioners consider the ages, developmental level of learners, and the context of instruction when scheduling group meetings.

The length of the session should reflect the ages and developmental levels of learners as well as the context of instruction. For instance, younger learners will generally have shorter sessions. Also sessions that focus on pre-teaching (or advance shadowing) before a social context, such as prompting social behaviors before going to recess or lunch, may be shorter than those that include a longer practice time within the context of group instruction.

\section{Step 5. Creating a Training Format or Structure}

1. Teachers/practitioners clearly identify a format with set beginning/ending times and time for various activities.

2. Teachers/practitioners insure that the format includes at least an introduction, instruction, practice, and feedback with reinforcement.

Social skills training group sessions should be carefully formatted to clearly identify date/schedules for the sessions, the purpose of the session, the members of the group, expectations for the session, beginning and ending times, and the location of the sessions. For some learners, a visual schedule of events should ease anxiety about the group.

3. Teachers/practitioners select a format appropriate for the age and characteristics of the learners in the group.

To make the best use of time set aside for social skills training groups, it is especially important to have a carefully planned format for the session. If the format is planned and adhered to, learners will be more likely to successfully acquire the targeted skills. In addition, both learners and leaders/helpers will enjoy the sessions and want to continue participating. The format chosen may vary according to the types of skills being taught, the setting for instruction, and the time allotted for the session. In the evidence base studies, most social skills groups used a format that included an opening and closing time with instruction and practice time embedded in the middle. A general format may include the following components:

a. introduction/warm-up. In this phase, everyone settles into the group time. Introductions are made initially, but may need to be repeated for at least the first few sessions if group members do not already know one another. Having both leaders and learners sit in a circle and take turns introducing themselves was often used during this introductory/warm-up time. (Some facilitators ask learners to pass an object, such as a small rubber ball, from person to person as they share.) At subsequent meetings, participants can be asked to introduce one another, if 
National Professional Development Center on Autism Spectrum Disorders

\section{Module: Social Skills Groups}

appropriate. After group members become familiar with one another, this introductory/warm-up time may be used to discuss experiences in using the target social skills from the previous week (or the time between meetings, if it is not a weekly group time).

b. topic focus. The group leader will introduce the topic or focus of instruction for the session. This component of the session may also be a good time to review skills that were previously learned and to ask if anyone has questions or concerns. As group members become more comfortable with one another and the format, individuals can take turns reviewing and sharing from prior weeks.

c. modeling. Once the topic for the week has been clearly identified, the target skill should be modeled. Modeling may be done by group leaders and helpers, with group members themselves, or with video modeling. The goal of this phase is for group members to observe the target behavior or skill being practiced correctly and successfully. Some groups may find it helpful to have both good and bad examples of the behavior and/or target skill component. Before moving on to practice and/or rehearsal, group leaders should ask for questions or comments.

d. practice. After learners have seen a model of the behavior, time should be provided for practice of the new skill or behavior, often through role-playing, (i.e., having participants pair off and take turns practicing the skill). Learners should have several opportunities to practice the new skill or behavior in the safety of the group. Teachers/practitioners may choose to video record participants (with permission of the learner and his/her parent/guardian, of course) as they practice so that they can watch the videos and talk about what they did right and what they might do differently the next time. Videos may also be sent with learners so that they can review them outside of group time. For more information please refer to resources on Video Modeling developed by the National Professional Development Center on Autism Spectrum Disorders.

e. coaching/prompting. Depending on the skills being taught, the group may go into a more inclusive environment (e.g., a shopping mall) and practice the skills with strangers, while receiving coaching from group leaders and helpers. Regardless of the setting, group members must have someone available to provide support and prompting as needed. The type and amount of prompting should be individualized based on the characteristics of the individual learner. For more information on Prompting, please see resources developed by the National Professional Development Center on Autism Spectrum Disorders.

f. feedback/problem solving. Generally, this phase of instruction is integrated within the practice element. To be successful, participants must receive detailed feedback on their use of the target skill or behavior. Leaders and helpers should emphasize skills that the participants implemented correctly. For behaviors/skills that need improvement, leaders should help learners to identify corrective strategies and alternative responses. 
National Professional Development Center on Autism Spectrum Disorders

\section{Module: Social Skills Groups}

g. free/snack time. Because the social skills group should remain a positive and motivating activity for participants, adults/leaders should include reinforcers as a regular part of the session. Reinforcement may be provided at the end of the session, or it may be embedded within the training sessions during a slightly less structured snack time that allows participants to interact with one another without being evaluated. The free/snack time component of the session may also be a good time to provide interactive materials such as card or board games or a topic for discussion (e.g., one teacher uses funny YouTube videos as the springboard for students to have a conversation). For more information, please refer to resource on Reinforcement developed by the National Professional Development Center on Autism Spectrum Disorders.

Step 6. Organizing Topics for Instruction

1. Teachers/practitioners break large topics of instruction (e.g., conversation skills) into more teachable units (e.g., initiations, turn-taking, asking questions, terminating).

Depending on the social skill or skill group being taught, it may be necessary to break skills down (using task analysis) into smaller increments that can be taught sequentially. Using the example of conversation skills, the following sub-topics may be addressed sequentially during the topic focus or instructional time, with opportunities for the entire set of skills to be practiced later in the session:

- initiating conversations,

- responding to initiations of others,

- taking turns talking during conversation,

- changing topics during a conversation,

- asking questions during a conversation,

- strategies for what to do when you disagree during a conversation

- inviting a third person into a conversation,

- leaving a conversation, and

- ending a conversation.

In this example, the social skills training group focused on conversation skills. These skills could be taught throughout a semester, with the first session designated for getting to know one another and providing an overview of what the group will involve. Each of the next nine sessions might focus on a specific sub-skill or focus on a sub-skill for more than a week, if necessary. The final session of the semester could be designated as a wrap-up time, providing an extended opportunity to practice the learned skills in a safe social context or to celebrate the group's accomplishments.

\section{Step 7. Specifying Embedded Instructional Strategies or Materials}

1. Teachers/practitioners identify additional instructional strategies (e.g., social narratives, video modeling) for promoting skill development. 
National Professional Development Center on Autism Spectrum Disorders

\section{Module: Social Skills Groups}

Using other strategies and/or high interest materials may help bring learners to the group, sustain interest/motivation, and increase meaningful learning opportunities. In one of the evidence-based studies, researchers used video modeling to teach appropriate play and social behaviors. The videos, using peer models, were shown prior to the play time during which the young learners could practice the skills. Before and after the video and play times, a circle time was used to orient group members to the topic and to assist with transition out of the group time. In another study, a social narrative was used with group members who were learning to interact more with peers in cooperative learning contexts, during organized sports, and during lunch. Some other instructional strategies that may be used within the context of group instruction include peer modeling, self-modeling, role playing, computer-aided instruction, and the use of visual supports. Please refer to resources on Peer-Mediated Instruction and Intervention, Computer-Aided Instruction, and Visual Supports developed by the National Professional Development Center on ASD for more information on these practices. Remember also to document strategies used and how they were combined within the group instruction format.

2. Teachers/practitioners provide appropriate resources (e.g., interactive toys, books or social narratives, videos) for specific skills that are the focus for group training.

Before the social skills session, group leaders should have all necessary materials available and ready to use during group time. Planning for resources is usually accomplished during Steps 5 and 6 . Some examples of materials that may enhance the group training include interactive toys (e.g., such as Legos ${ }^{\mathrm{TM}}$ ), video games for two or more players, and board or card games. Teachers/practitioners should avoid having too many materials that could be used as an escape or isolated play activity, tempting learners not to participate in the group training.

\section{Step 8. Training Helpers Prior to Implementing Group Instruction}

Teachers/practitioners will have identified and recruited helpers in Step 2 . In addition, if helpers have little or no experience working with learners with ASD, they should be given instructions on working with learners with ASD and should be given opportunities to become familiar with the learners in the group. For example, having the helper spend some unstructured time with learners in the school setting should help prepare them for interactions during the social skills group. In addition, some additional orientation and/or training specific to the group instruction may be required.

1. Teachers/practitioners train helpers on group instruction, data collection, and help them become familiar with strategies and materials

Specifically, teachers/practitioners review the goals of the group instruction, provide an overview of how training will be done, and provide time for helpers to become familiar with the topic and materials. In addition, teachers/practitioners train helpers on the use of data sheets to collect baseline, intervention, and generalization data for progress monitoring.

2. Teachers/practitioners regularly provide time to confer with helpers to discuss learner progress; questions that have emerged; and to review goals, priorities, and status of social skills group activities. 
National Professional Development Center on Autism Spectrum Disorders

\section{Module: Social Skills Groups}

Teachers/practitioners and helpers must have time (in addition to social skill group sessions) to review data, discuss student progress, problem solve, and adapt instruction as necessary. The amount of time will vary, but plan on a minimum of a half an hour each session. An easy way to accomplish this is to have the leaders and helpers stay for half an hour after the training has ended and the learners have left and/or have them arrive before the social group session to review and prepare before learners arrive.

\section{Step 9. Implementing Social Skills Group Training}

1. Teachers/practitioners conduct social skills group training regularly, as planned.

The most important aspect of social skills group training, of course, is actually implementing the social skills group training. As previously suggested, teachers/practitioners should plan for a minimum of 12 sessions per semester (if held weekly) and taking into account school holidays and breaks. Group training can occur for shorter or longer periods of time, depending on learner needs and progress, as well as the complexity and number of skills being taught. Implement the social skills training groups following the format chosen in Step 5.

\section{Step 10. Collecting and Using Data on Target Behaviors/Skills to Inform Instructional Decision Making}

1. Teachers/practitioners (and/or helpers) collect data on target behaviors/skills over time, including baseline data (i.e., data on the behavior or skill prior to intervention/instruction).

2. Teachers/practitioners collect data on intervention/instruction (e.g., type and number of prompts used to elicit target behavior).

Data collection is an integral part of social skills group training. Prior to intervention, baseline data documents that instruction is necessary and establishes the starting point for instruction (see ABC Data Collection example). Once a program has begun, data collection documents learner progress and informs instructional decision making. Data may be collected in a variety of ways depending on the behaviors or skills targeted for instruction as well as features of the intervention. For instance, in the example of training conversation skills, frequency (i.e., how often a behavior occurs) may be collected on various aspects of making conversations (e.g., initiations, turn-taking, terminating conversations). Another measure might be the amount of pause time between an initiation and the communicative partner's response. Other types of data may include voice quality or tone during the conversation or how the learner is positioned in relation to his communicative partner. In addition, notes may be taken regarding the effectiveness of the learner's attempts at conversation. Some group facilitators may find it helpful to video record the practice time following instruction and then play the video back to the group so that members can analyze their own conversational skills and provide feedback to one another. If using video recording, data may not have to be collected during the actual training time, it might be taken from review of the video at a later time. Please see the accompanying Social Skills Training Group Sample Data Sheet for one example of the type of data that may be collected on specific social skills. 
National Professional Development Center on Autism Spectrum Disorders

\section{Module: Social Skills Groups}

3. Teachers/practitioners collect data on generalization of target behaviors to other settings and with other people.

Generalization data may be gathered in a variety of ways, including observations in other settings and with other people. Information on the target skill (e.g., number of conversational initiations in the cafeteria at school) can be recorded, while taking care to avoid being socially intrusive. A more subtle way of gathering data in such circumstances is to recruit another adult to casually observe and make notes on the target skill. Another option is to have learners with ASD report back to you, thus collecting data on their own behavior, a component of selfmanagement. Please refer to Self-Management: Steps for Implementation (National Professional Development Center on ASD, 2008) for more information about selfmanagement.

\section{Teachers/practitioners summarize or graph data.}

As discussed in Step 8, having a regular time for teachers/practitioners and helpers to meet outside of group time to manage and review data and discuss learner progress is an important part of the group process. During this time, group leaders can summarize and/or graph data. How the data are managed will be a reflection of the type of social skills being trained. For conversation training, for instance, leaders will likely have a single data sheet on which they have recorded information on participants' target skill use during the training session. From this sheet, they can transfer each learner's data to a sheet that reflects only that learner's target skill(s). To use the earlier example, this would mean that from the group conversation skills group data sheet, the leader would transfer specific information about the number of initiations made by Joe (e.g., a simple line graph showing frequency of interactions over time), the presentation of Tom's initiations (e.g., notes detailing whether or not he was standing still and speaking at an appropriate volume), and the wait time or delay that Matt allowed between initiations with others (e.g., a bar graph representing the amount of time allowed by count or seconds). See the accompanying examples of how these data could be graphed at the end of this document.

5. Teachers/practitioners use data to make instructional decisions.

Once data have been collected and summarized and/or graphed, data are used to make instructional decisions. These decisions may include:

- beginning group instruction. Baseline data should show a stable trend before beginning instruction. A stable trend is indicated by data points that are similar in frequency/intensity. It is also appropriate to begin instruction if the baseline data are not stable, but are moving away from the desired level of the skill. For instance, if baseline data collection indicated that Matt was leaving less and less time for conversational partners to respond or if his interfering behavior was beginning to escalate (e.g., he was showing signs of frustration with the lack of an immediate response), it would be appropriate to discontinue baseline data collection and begin intervention. 
National Professional Development Center on Autism Spectrum Disorders

\section{Module: Social Skills Groups}

- continuing group instruction. Data taken during social skills training groups may show that learners are making progress in acquiring the target skills or behavior, providing evidence that group instruction should continue. Data may also show that little or no progress is occurring, suggesting that the instruction may need to continue for a longer time period or perhaps be changed in some way (e.g., increase the frequency or length of training sessions)

- changing group instruction. Data taken on the type and amount of instructional prompts may suggest the need for changes in instruction. For instance, once a learner is able to successfully use a target skill when given verbal prompts, the instructor would begin to phase out verbal prompts so that the learner might begin using the skill more independently.

- discontinuing group instruction. Data also provide documentation to support discontinuation of instruction in a particular area. If data demonstrate that the learner has reached the goal of instruction, it may be time to reduce the amount of instruction for that learner or turn the focus toward generalization of the skill to other settings, people, or situations.

In this age of educational accountability and increasingly limited resources, using data to inform and support instructional decisions is a must! Before beginning, changing, or discontinuing any type of instruction, such as social skills groups, data must be collected on the specific behavior or skill and the progress that has been made by the learner. 


\section{Appendix E}

The Relationship between Social Skills and Problem Behaviors in Adolescent Males with Autism

$$
\text { Spectrum Disorder }
$$

\section{Literature Review}

This literature review will cover the relevant aspects of social skills training as it relates to adolescent males with autism. More specifically, those who display some form of problem behaviors in the classroom. Autism is a developmental disability that often affects the social interaction abilities and communication patterns of the individual. Research has indicated that social skill deficits and the presence of problem behaviors often contribute to a lack of friendships, prevent social inclusion, and contribute to academic and occupational underachievement (Williams White, Keonig, \& Scahill, 2007).

The focus of this literature review is to gain an understanding of the process for social skills training and the possible impact of social skills training on problem behaviors for adolescent males with autism. This literature review will begin with an understanding of social skills and the assessment of those skills. Social skills training is then explored, followed by options for teaching social skills and a closer look at the Super Skills program, which is used for this research.

\section{Social Skills}

Social skills are those behaviors that we learn and enable us to interact with others (Bellini \& Peters, 2008). Those working with students with autism should review assessment results and current research to make decisions regarding intervention for improving social abilities and teaching social skills. Researchers have attempted to discover what structures of the brain are involved in social skills and to understand what behaviors are necessary for social 
processing (Kupperman, 2012). The skills of eye gaze, eye gaze following, joint attention, face recognition, emotion recognition, speech, language development, theory of mind, and imitation are behaviors that are necessary for engaging in social situations (Kupperman, 2012; von dem Hagen, Stoyanova, Rowe, Baron-Cohen, \& Calder, 2013).

Increases in the skills mentioned above enhance the ability of individuals with autism to interact with their peers and participate in community activities (Stichter et al., 2010). However, acquiring social skills is challenging for adolescents who have autism, as social skills may not be intrinsically motivated. They also may not readily have the ability to identify and utilize social cues, as effective as their typical peers. Interventions addressing social abilities are critical to the lifelong abilities of individuals with autism and should be evidence-based. One such intervention is social skills training. Social skills training teaches new social skills, reinforce the current level of social functioning, and assist in generalizing skills across settings and people (Bellini \& Peters, 2008).

\section{Social Skills Assessment}

Social skills assessment is a method of gaining information about an individual's current level of social functioning regarding strengths and needs. This assessment should be used to guide appropriate interventions and progress monitoring options. Stichter et al. (2010) indicated that repeating an assessment over time with the same individual is necessary to signify pre/post progress as well as ongoing growth in areas of social competence. Assessment methods can be in the form of interviews or formal evaluations and based on the skills and abilities of same-aged, typically developing peers. The measurement of the individual's social abilities is essential for selecting activities for intervention. 
For this research, the Social Responsiveness Scale (SRS) is used to measure autism symptomatology in the self-contained classroom setting. The SRS measures the severity of autism symptoms as observed by caregivers and teachers in the individual's natural setting (Pearl, Murray, Smith, \& Arnold, 2013). In the SRS School-Age form, scores are obtained for five treatment subscales: Social Awareness, Social Cognition, Social Communication, Social Motivation, and Restricted Interests and Repetitive Behavior (Souter, 2011). The SRS is not a replacement for other clinical diagnostic tools and assessments but an efficient form of autism symptomatology and severity. Pearl et al. (2013) examined the interrater reliability of parent ratings of their children's social competence. The SRS was used to measure the severity of autism symptoms as observed by caregivers in the natural setting. Intraclass correlations of all subscales between mothers and fathers were statically significant with the communication subscale, demonstrating the highest correlation across informants (Pearl et al., 2013). Results suggested that the SRS is an efficient tool for seeking a more comprehensive understanding of social skill deficits. They also indicated that if both parents are in one environment, it may not be necessary to include ratings from both to gain an accurate assessment of the child's behavior.

When using the SRS assessment, it is necessary to consider outside factors that might influence the scores. Hus, Bishop, Gotham, Huerta, and Lord (2013) sought to understand how individuals' SRS results are affected by non-autism-specific conditions such as age and language level. Previously, other parental factors such as education level and frame of reference have been acknowledged as influences and possible limitations to SRS scores. Participants of Hus et al. (2013) were 2,368 individuals with autism and 1,913 siblings without autism. Results of this study indicated that SRS scores were strongly associated with behavior problems for children with autism and their unaffected siblings. Effects of age and expressive language were small but 
significant. Results also suggested that SRS measurement of social impairment scores are exaggerated within older children with autism who have more significant behavior problems. This information is imperative as the participant's problem behaviors range from modest to severe. Some are self-inflicting behaviors while others are aggressions on peers, teachers or parents. These problem behaviors are likely to inflate SRS scores because the outcomes of frequent problem behaviors can have the same outcomes as someone who has autism.

Increasing the social skills of adolescent males with autism requires interventions that explicitly teach desired social skills and allow for consideration of individual needs. Increases in social abilities can contribute to success in many areas of an individuals' life both during and after high school (Carter et al., 2013). Assessment of social skills for an individual with autism is essential to understand where the individual has social deficits. Based on a review of assessment options, the SRS School-Age form is used in this research. The SRS is the preferred scale because it demonstrates significant strength in quantitatively measuring traits of autism across the range of autism severity and allows the identification of characteristics of autism (Wilkinson, 2010). The SRS takes $15-20$ minutes to complete and is relatively easy to administer as compared to other assessments mentioned above, which can take up to two hours to administer (Murray, Mayes, \& Smith, 2011).

In conjunction with the SRS, the Profile of Social Difficulty (POSD) from the Super Skills program will be used. Coucouvanis (2005) introduced the POSD as a tool to help determine a baseline of social behaviors and identify gaps in social interaction skills. There is no specific research on the POSD assessment, but this assessment is recommended for use with the Super Skills Program and has a direct correspondence to the suggested lessons. There must be a correspondence between assessment and intervention to allow identification of changes in social 
behavior (Gresham, Sugai, \& Horner, 2001). Coucouvanis (2005) has recommended this tool for individuals with autism age range 6-11 years, but it has not received peer review. Therefore, it is used in conjunction with the SRS tool. The results from the POSD will be used to determine the schedule of lessons in the Super Skills curriculum.

\section{Social Skills Training for Adolescents with Autism}

There are many social skills interventions, but those that have previously demonstrated the effectiveness and display some form of generalization across time and situations are recommended (Odom \& McConnell, 1992). Social skills training has been documented as an evidenced-based practice for increasing social skills, increasing communication and social abilities, and decreasing problem behaviors (Cotugno, 2009; National Professional Development Center on Autism Spectrum Disorder, 2015; Stichter et al., 2010). Social skills training meets evidence-based criteria through seven group design studies and eight single case design studies and has been effective in improving outcomes in social, communication, and behavior of individuals with autism ages 6-14 years (Wong et al., 2014). The following studies analyzed social skills training programs and their ability to increases social skills in individuals with autism. These studies are foundational for the selection of programs to teach social skills to adolescents with autism.

\section{Sociodramatic Affective Relational Intervention (SDARI) and Skillstreaming.} Sociodramatic Affective Relational Intervention (SDARI) and Skillstreaming were evaluated by Lerner and Mikiami (2012) in a preliminary randomized controlled trial. The SDARI is based on social skills interventions and uses games to reinforce social skills and to motivate successful social interactions. Skillstreaming focuses on teaching behavioral steps to individuals who may not have the necessary skills to be successful in social situations (Goldstein \& McGinnis, 1997). 
There were 13 participants with autism randomly assigned to 4 weeks of SDARI or Skillstreaming for 1-day per week. The Social Communicated Questionnaire (SCQ) and the SRS were used to support the participants' previous diagnosis of autism. Participants of the SDARI or Skillstreaming groups demonstrated no difference in baseline social functioning, but both groups increased reciprocated friendship nominations and social skills post-intervention. There were no reports of increases in social functioning by parents. Researchers attributed this lack of generalization across social contexts to the short intervention duration. It was also concluded that an increase in the amount of communication with parents regarding the interventions would have helped parents have an interest in teaching and reinforcing targeted skills in the home.

Social Competence Intervention (SCI). Stichter et al. (2010) researched the Social Competence Intervention (SCI), an intervention targeted at addressing the social needs of youth with high functioning autism and Asperger's syndrome. SCI is designed to teach new social skills as well as allow participants opportunities to practice skills in a naturalistic setting. SCI included five units with specific target skills and constructs (Stichter et al., 2010). The group interventions consisted of 20 hours conducted twice weekly for ten weeks. Students with autism between age 11-14 years who spent a portion of their day with neurotypical students were identified. The students with autism demonstrated growth in four of the five units: social abilities, facial expression recognition, the theory of mind, and executive functioning. Therefore, SCI is an effective curriculum when looking to increase the social abilities of early adolescents with autism.

Social Skills Training Groups. When searching for social skills training interventions for this research, the aforementioned social skills training interventions have research to support them, but they are costly and require extensive training for the implementer before beginning 
programming. Coucouvanis (2005) introduced Super Skills as a social skills curriculum for teaching individuals with autism social skills. Unlike some social skills training programs, Super Skills has not received peer review, but it is based on the research of social skills training groups. Social skills training groups aim to increase social interactions and communication abilities. Social skills training group programs have different social targets and activities to achieve desired outcomes vary, but the idea is for two to six individuals with autism to rehearse and practice social skills while receiving reinforcement form implementers or peers (Hotton \& Coles, 2016; Sansosti, 2010; Wong et al., 2014).

Tse, Strulovitch, Tagalakis, Meng, and Fombonne (2007) evaluated social skills training groups for adolescents with high autism and Asperger's syndrome. Psychiatry and community clinics referred to 46 adolescents (age 13-18 years) for participation. Parents of participants completed the Social Responsiveness Scale (SRS), the Aberrant Behavior Checklist (ABC), and the Nisonger Child Behavior Rating Form (N-CBRF) to assess social skills and problem behavior pre and post-treatment. Adolescent participants were asked for their input regarding their like/dislike for the social skills group and perceived improvements. Implementation occurred over 12 weeks for 60-90 minutes each week.

The social skills training group used role-play, psychoeducational, and experiential methods of teaching. A standard sequence of activities for each session was developed, covering various social skills throughout the 12 weeks. Social skills covered included: awareness and expression of feelings, making eye contact, recognition of non-verbal communication, politeness, introducing oneself to others, listening to others, starting a conversation, maintaining a conversation, ending a conversation, making small talk, negotiating with others, responding to teasing and bullying hygiene, dining etiquette, and dating etiquette. Results of the social skills 
training groups found significant gains from implementation to completion for social skills and problem behaviors. The SRS subscale improvements were statistically significant and ranged from .34 to .46 , and. Problem behaviors decreased with effect sizes ranging from .34 to .72 postintervention, suggesting that social skill training groups are an effective method for adolescents with autism to increase levels of social interactions and decrease problem behaviors.

\section{Problem Behaviors}

Studies on social skills training often focus on increasing social skills, but in addition to social and communication deficits, individuals with autism may engage in socially unacceptable behaviors or problem behaviors that may harm themselves or others. Problem behaviors are those that are problematic because they may be physically dangerous or may impede the learning of the individual with autism or their peers (Matson \& Nebel-Schwalm, 2007).

When looking for effective interventions to increase the social abilities of individuals with autism, it is beneficial to consider interventions that decrease the occurrences of problem behaviors. Social skills training is one method to increase the social functioning of individuals with autism, but a possible additional effect of social skills training could be the reduction of problem behaviors (Wong et al., 2014).

Lyons, Huber, Carter, Chen, and Asmus (2016) found that individuals with autism have below average social skills and above average occurrences or problem behaviors. From the perspective of applied behavior analysis, a Functional Behavior Assessment (FBA) is used to determine the motivation or function of problem behavior. FBAs work to establish functionally equivalent replacement behaviors and methods for decreasing problem behaviors (Cooper, Heron, \& Heward, 2007). Though FBAs are effective when working to decrease problem behaviors in individuals with autism, they are often time-consuming and take extensive training 
to complete. Some problem behaviors can be prevented or reduced if social functioning is increased (Boyd, McDonough, \& Bodfish, 2012); one way to do this involves specific social skills training, which is required to increase social functioning for students with autism.

Tse et al. (2007) implemented social skills training groups for individuals with Asperger's and autism. Through their research, they found that social skills training groups were not only useful for increasing participants social abilities, but there were significant improvements in some of the participants' problem behaviors. Moreover, the behaviors more closely associated with autism, such as regulation problems, anxiety, self-isolation, stereotypical behaviors, and self-injurious behaviors, all demonstrated improvements. Externalizing behaviors did not have significant improvements in response to social skills training. Indicating that for individuals with autism, some problem behaviors but not all, might be impacted by social skills training (Tse et al., 2007).

Social skills training requires an understanding of the individual's current level of social functioning, effective teaching practices, and assessment of outcomes related to social skills training. When individuals with autism exhibit problem behaviors, it impedes the development of socially skilled behaviors (Gresham \& Elliott, 1990). Addressing social skills during adolescence is important as these students are nearing an age where they will transition into community settings and be expected to function more independently. Using the Super Skills program, this study will examine the effects of social skills training on the social behaviors and problem behaviors of adolescent males with autism. The results will determine if an increase in social skills reduces problem behaviors for the individuals. 


\section{References}

Bellini, S., \& Peters, J. (2008). Social skills training for youth with autism spectrum disorders. Child and Adolescent Psychiatric Clinics of North America, 17, 857-73. doi:10.1016/j.chc.2008.06.008

Boyd, B. A., McDonough, S. G., \& Bodfish, J. W. (2012). Evidence-based behavioral interventions for repetitive behaviors in autism. Journal of Autism and Developmental Disorders, 42, 1236-1248. doi:10.1007/s10803-011-1284-Z

Cooper, J. O., Heron, T. E., \& Heward, W. L. (2007). Applied behavior analysis (Vol. 2). Upper Saddle River, NJ: Pearson/Merrill-Prentice Hall.

Cotugno, A. J. (2009). Social competence and social skills training and intervention for children with Autism Spectrum Disorders. Journal of Autism and Developmental Disorders, 39, 1268-1277. doi:10.1007/s10803-009-0741-4

Coucouvanis, J. (2005). Super skills: A social skills group program for children with Asperger syndrome, high-functioning autism and related disorders. Shawnee Mission, KS: Autism Asperger Publishing Co. doi:10.1109/TAC.2017.2744499

Goldstein, A., \& McGinnis, E. (1997). Skillstreaming the adolescent. Champaign, IL: Research Press.

Gresham, F., \& Elliott, S. (1990). Social skills rating system. Circle Pines, MN: American Guidance Service.

Gresham, F. M., Sugai, G., \& Horner, R. H. (2001). Interpreting outcomes of social skills training for students with high-incidence disabilities. Exceptional Children, 67, 331-344. 
Hotton, M., \& Coles, S. (2016). The effectiveness of social skills training groups for individuals with autism spectrum disorder. Review Journal of Autism and Developmental Disorders, 3, 68-81. doi:10.1007/s40489-015-0066-5

Hus, V., Bishop, S., Gotham, K., Huerta, M., \& Lord, C. (2013). Factors influencing scores on the social responsiveness scale. Journal of Child Psychology and Psychiatry, 54, 216224.

Kupperman, P. (2012). The source for social competency. East Moline, IL: LinguiSystems, Inc. Lerner, M., \& Mikami, A. (2012). A preliminary randomized controlled trial of two social skills interventions for youth with high-functioning autism spectrum disorders. Focus on Autism and Other Developmental Disabilities, 27, 147-157.

Lyons, G., Huber, H., Carter, E., Chen, R., \& Asmus, J. (2016). Assessing the social skills and problem behaviors of adolescents with severe disabilities enrolled in general education classes. American Journal on Intellectual and Developmental Disabilities, 121, 327-45. doi:10.1352/1944-7558-121.4.327

Matson, J., \& Nebel-Schwalm, M. (2007). Assessing challenging behaviors in children with autism spectrum disorders: A review. Research in Developmental Disabilities, 28, 567 579. doi:10.1016/j.ridd .2006 .08 .001

Murray, M., Mayes, S., \& Smith, L. (2011). Brief report: Excellent agreement between two brief autism scales (checklist for autism spectrum disorder and social responsiveness scale) completed independently by parents and the autism diagnostic interview-revised. Journal of Autism and Developmental Disorders, 41, 1586-1590.

National Professional Development Center on Autism Spectrum Disorder. (2015). About the NPDC / Autism PDC. Retrieved from http://autismpdc.fpg.unc.edu/about-npdc 
Odom, S., \& McConnell, S. (1992). Improving social competence: An applied behavior analysis perspective. Journal of Applied Behavior Analysis, 25, 239-244.

Pearl, A., Murray, M., Smith, L., \& Arnold, M. (2013). Assessing adolescent social competence using the Social Responsiveness Scale: Should we ask both parents or will just one do?. Autism, 17, 736-742.

Sansosti, F. (2010). Teaching social skills to children with autism spectrum disorders using tiers of support: A guide for school-based professionals. Psychology in the Schools, 47, 257281. doi:10.1002/pits.20469

Souter, K. (2011). A best practice guide to assessment and intervention for autism and Asperger syndrome in schools. Educational Psychology in Practice, 27, 97-97. doi:10.1080/02667363.2011.549693

Stichter, J. P., Herzog, M. J., Visovsky, K., Schmidt, C., Randolph, J., Schultz, T., \& Gage, N. (2010). Social competence intervention for youth with Asperger syndrome and highfunctioning autism: An initial investigation. Journal of Autism and Developmental Disorders, 40, 1067-1079. doi:10.1007/s10803-010-0959-1

Tse, J., Strulovitch, J., Tagalakis, V., Meng, L., \& Fombonne, E. (2007). Social skills training for adolescents with Asperger syndrome and high-functioning autism. Journal of Autism \& Developmental Disorders, 37, 1960-1968. doi:10.0.3.239/s10803-006-0343-3

Wong, C., Odom, S. L., Hume, K., Cox, A. W., Fettig, A., Kucharczyk, S., \& Schultz, T. R. (2014). Evidence-based practices for children, youth, and young adults with autism spectrum disorder. Retrieved from http://autismpdc.fpg.unc.edu/sites/autismpdc.fpg.unc.edu/files/2014-EBP-Report.pdf Williams White, S., Keonig, K., \& Scahill, L. (2007). Social skills development in children with 
autism spectrum disorders: a review of the intervention research. Journal of Autism and Developmental Disorders, 37, 1858-1868. doi:10.1007/s10803-006-0320-х 